Cruz Gutiérrez, David Fernando, "Mujeres, atrocidad y castigo: un estudio de caso sobre las razones del movimiento de mujeres para penalizar el feminicidio en Colombia", Nuevo Foro Penal, 93, (2019).

\title{
Mujeres, atrocidad y castigo: un estudio de caso sobre las razones del movimiento de mujeres para penalizar el feminicidio en Colombia
}

\author{
Women, atrocity and punishment: a case study \\ about the reasons of the women's movement \\ to criminalize feminicide in Colombia
}

David Fernando Cruz Gutírrrez ${ }^{*}$

Fecha de recepción: 28/05/2019 - Fecha de aceptación: 27/09/2019

DOI: $10.17230 /$ nfp.15.93.5

\section{Resumen}

El movimiento de mujeres tanto en Colombia como en el mundo tiene una larga tradición en el uso del derecho. Este trabajo, además de dialogar con la literatura sobre este tema, pretende analizar otra arista de la relación del derecho penal con los movimientos de mujeres que centra su mirada, ya no en las profundas críticas planteadas al derecho penal, sino en la creciente demanda punitiva por parte de estos movimientos.

Abogado de la Universidad Nacional de Colombia. Magister en Derecho Universidad de los Andes. Profesor de Catedra de la Universidad de los Andes. Abogado del Área de Incidencia Nacional de Comisión Colombiana de Juristas. E-mail: df.cruz@uniandes.edu.co. Agradezco al Profesor Libardo José Ariza Higuera por su constante aliento en la escritura de la tesis de maestría que daría lugar a este artículo. 
168 Mujeres, atrocidad y castigo: un estudio de caso sobre las razones del movimiento de mujeres para penalizar el feminicidio en Colombia - David Fernando Cruz Gutiérrez

\section{Abstract}

The women's movement in both Colombia and the world has a long tradition in the use of law. This work, in addition to dialogue with the literature on this subject, aims to analyze another aspect of the relationship of criminal law with women's movements that focuses its gaze, not on the deep criticism raised in criminal law, but in the growing punitive demand by these movements.

\section{Palabras clave}

Derecho penal - movimiento de mujeres - lucha de género - violencia de género.

\section{Keywords}

Criminal law - women's movement - gender struggle - gender violence.

\section{Sumario}

Introducción: el síndrome de Estocolmo. 1. Una insatisfactoria respuesta: el papel de los movimientos sociales en la demanda punitiva. 2. Las mujeres y el derecho penal: una engañosa tentación. 3. El movimiento de mujeres en Colombia: la lucha por el derecho. 4. La atrocidad: el caso de Rosa Elvira Cely. 5. La respuesta punitiva: del proyecto 107 de 2012 a la Ley Rosa Elvira Cely. 6. Una respuesta compleja. 6.1 Las razones pragmáticas. 6.2 De la atrocidad a la oportunidad política. 6.3 Una proximidad inesperada: el feminicidio como funcionalismo radical. 7. Bibliografía.

\section{Introducción: el síndrome de Estocolmo}

El movimiento de mujeres tanto en Colombia como en el mundo tiene una larga tradición en el uso del derecho1. En Colombia, este movimiento existe desde hace más de medio siglo, pero, tal como lo resaltan varios autores de la academia legal, es solo hasta la entrada de la Constitución en 1991 que el movimiento se entregaría a la movilización legal23. Estas reivindicaciones legales han estado acompañadas de

1 Bergalli y Bodelon, "La cuestión de las mujeres y el derecho penal simbólico". Anuario de Filosofía del Derecho (ix), 1992, Madrid España, Ministerio de Justicia, 1992, pp. 43-73; BaER A, Judit "Feminist Theory and the Law" en The Oxford Handbook of Law and Politics. Caldeira A.G., Kelemen D. \& Whittington E. (Eds), Oxford: Oxford Press University, 2008; LarRauri, Elena Criminología crítica y violencia de género. Madrid: editorial Trotta, 2007.

2 Jaramillo, ISABel, "Reforma legal, feminismo y patriarcado en Colombia: el caso de la ley de Cuotas para mujeres en cargos de alto nivel en la Rama Ejecutiva". En Mas allá del derecho. Justicia y género en America Latina, L. Cabal ed. Bogotá D.C.: Siglo del hombre editores/Center for Reproductive Rights/ Universidad de los Andes, 2005, pp. 59-144; LemaitRe RiPoll, JuLIETA, El derecho como conjuro: fetichismo legal, violencia y movimientos sociales. Bogotá D.C.: Siglo del hombre editores/Universidad de los Andes. 2009; Lehouco Mazuera, Emilio, “Constitución de 1991, ley de Cuotas y movimiento feminista: el papel del derecho en la generación de estructuras de movilización, en Precedente, 2006, pp. 13-41.

3 Cabe afirmar que este no refleja un consenso en el movimiento feminista. Por el contrario, aún persisten debates sobre si la movilización legal es el camino adecuado para transformar la sociedad 
amplias reflexiones políticas, sobre las posibilidades del activismo jurídico para la consecución de cambios deseables en la sociedad. De esta forma, han focalizado sus esfuerzos en vislumbrar qué tipo de herramientas jurídicas y cuáles estrategias de movilización legal pueden beneficiar transformaciones sociales, al tiempo que cuáles pueden truncarlas ${ }^{45}$.

En parte de esta literatura, el derecho penal aparece en la mira de incisivas y lucidas críticas que, en materia de género, desenmascaran su apariencia de neutralidad", argumentando que las normas penales destinadas a la mujer "reflejan y construyen una determinada visión de mujer"7 acorde con la forma como los hombres las ven y tratan ${ }^{8}$ . Como lo advierte Zaffaroni ${ }^{9}$, esta visión de la mujer está estructuralmente vinculada a su dominación y subordinación social, y sólo a través de la disminución y contención del poder punitivo es posible superar dicha condición de subordinación. En consecuencia, otra parte de la literatura se ha encargado de documentar los casos, mecanismos y estrategias en los que se ha logrado la contención del poder punitivo para desmontar normas penales que exigen para su comisión un sujeto activo cualificado de sexo femenino, como lo es una de las modalidades del delito de aborto.

Este trabajo, además de dialogar con esta literatura, pretende analizar otra arista de la relación del derecho penal con los movimientos de mujeres que centra su mirada, ya no en las profundas críticas planteadas al derecho penal, sino en la creciente demanda

0 si, por el contrario, los esfuerzos deben estar encaminados a consolidar una cultura del respeto y la igualdad que trascienda la creación de normas.

4 Jaramillo \& Sierra, (2008) asume que "el derecho es un factor que interviene en la distribución de recursos y poder, $y$, al mismo tiempo, es un discurso que impide modificar sustancialmente dicha distribución" (Pág. 198). Esta misma posición se encuentra en Jaramillo \& Alvear (2012).

5 Alvear, Helena y Jaramillo, Isabel Cristina, Feminismo y Crítica jurídica. El análisis distributivo como alternativa crítica al legalismo liberal. Bogotá D.C.: Siglo del hombre editores/Universidad de los Andes, 2012; Jaramillo, Isabel Cristina y Alfonso, Tatiana, Mujeres, cortes y medios: la reforma judicial del aborto. Bogotá D.C.: Siglo del Hombre Editores/Universidad de los Andes, 2008.

6 García Amado, Juan Antonio. "iTienen sexo las normas? Temas y problemas de la teoría feminista del derecho" en. Anuario de Filosofía del Derecho (IX) pp. 13-42., 1992; Cabe desatacar que otro tipo de estudios como los de RUSCHE \& KIRCHEIMER (2009), con un enfoque marxista, critican el derecho penal precisamente por su falta de neutralidad y su selectividad en el castigo, propiciando la defensa de un modelo liberal de protección de la propiedad privada.

7 Larrauri, Elena Mujeres y Sistema Penal. Violencia Domestica. Buenos Aires: Editorial S.R.L. 2008, p. 20.

8 Mackinnon, Catherine. Unmodified: Discourses on Life and Law. Cambrige Massachusetts: Harvard University Press, 1987; Cabe recordar, por ejemplo, que Mackinnon afirma "el derecho ve y trata a las mujeres como los hombres ven y tratan a las mujeres" (1983: 644).

9 Zaffaroni, Eugenio. "El discurso feminista y el poder punitivo" en Las tramas del poder punitivo, del género del Derecho Penal, Brigin (Ed.). Buenos Aires: CEADEL. 2000. 
170 Mujeres, atrocidad y castigo: un estudio de caso sobre las razones del movimiento de mujeres para penalizar el feminicidio en Colombia - David Fernando Cruz Gutiérrez

punitiva por parte de estos movimientos. Tanto es así que, en los últimos 10 años, en el contexto latinoamericano, se han llevado a cabo de manera exitosa un paquete de reformas a los códigos penales regionales ${ }^{10}$, cuya principal característica es la creación del tipo penal de feminicidio ${ }^{11}$, como un delito autónomo pero que usualmente también vienen acompañados por otras medidas auxiliares, como la limitación en el acceso a subrogados penales a quienes fueron condenados por esta conducta o por agresiones de contenido sexual.

Este grupo de reformas estuvieron acompañadas por la presión de los movimientos de mujeres en contextos de altos índices de violencia de género, quienes soportaron jurídicamente su demanda, gracias al respaldo que la Corte Interamericana de Derechos Humanos les dio en la sentencia Gonzáles y otros vs. México ${ }^{12}{ }^{13}$ del 16 de noviembre de 2009, en la cual la Corte IDH especifica que los Estados que hacen parte Pacto de San José, ante escenarios en los que presentan homicidios a mujeres por motivos de género, deben adoptar medidas para conjurar este tipo de violencia "en particular, deben contar con un adecuado marco jurídico de protección, con una aplicación efectiva del mismo y con políticas de prevención y prácticas que permitan actuar de una manera eficaz ante las denuncias"14.

10 En 2007, Costa Rica fue el primer país en integrar el término feminicidio en su legislación, sin embargo, se limitó al campo íntimo. Posteriormente en el 2008 Guatemala también integro este delito a su legislación esta vez, sin la limitación al campo íntimo. Este ejemplo lo siguió el Salvador país que en el 2010 aprobó, por medio de una ley especial, el delito de feminicidio para situaciones de odio 0 menosprecio por la condición de mujer. En Sudamérica el primer país en seguir esta tendencia fue Perú, quién en 2011 realizo las reformas legales concernientes. Sin embargo, en 2012 varios países de importancia regional se unieron a la lista, entre ellos México, Argentina, Chile y Nicaragua. En el 2013, se enlistaron los países de Bolivia y Panamá y finalmente, en el 2015, integraron el feminicidio a sus códigos penales Colombia y Brasil.

11 El termino feminicidio proviene lingüísticamente del inglés feminicide utilizado por los angloparlantes para describir las muertes producto de la violencia de género. Sin embargo, es heredero conceptual del termino genericidio acuñado y desarrollado por Mary Anne WarRen (1985) con el objetivo de describir la más alta probabilidad que tienen las mujeres de morir o sufrir mutilaciones a manos de un hombre que por enfermedades, accidentes y guerras En Latinoamérica el termino incursiono gracias al trabajo de la antropóloga Marcela LAgarde (1997; 1999), quien lo utilizo para describir el sistemático asesinato de niñas y mujeres en Ciudad Juárez, México. El termino tuvo una buena acogida por las autoridades locales y por algunos órganos de la ONU que lo replicaron en relativamente poco tiempo a otros contextos latinoamericanos, entre ellos Colombia.

12 En Dicha providencia la Corte IDH identifica que, dado el contexto Ciudad Juárez, los homicidios de las mujeres que estudia, fueron por razones de género. Si desea profundizar: http://www.corteidh. or.cr/docs/casos/articulos/seriec _ 205 _ esp.pdf

13 También conocida "como el caso Campo Algodonero vs México" (Agatón, 2017).

14 Corte IDH, González y Otros vs. México, 2009, párr. 258. 
Estas reformas han impactado en la política criminal regional, al establecer como uno de sus principales imperativos la protección penal de la mujer. A su vez, esto condujo a sanciones punitivas más graves para los delincuentes que incurrieran en conductas relacionadas con violencia de género. Por fuera del contexto latinoamericano, algunos criminólogos y penalistas que han estudiado la relación entre los movimientos de mujeres y la demanda punitiva, han advertido que el uso del discurso penal por parte de los movimientos de mujeres ha terminado revalidando la expansión punitiva ${ }^{15}$.

Este inquietante fenómeno da muestra de que el derecho penal es un artefacto cultural polifacético y complejo ${ }^{16}$ que es objeto, en un mismo contexto, de resistencia y deseo. Es esta alteridad la que ha servido como pináculo para orientar mis dudas frente al tema y es, en gran medida, la que sustenta el nombre de esta introducción titulada El Síndrome de Estocolmo. Pues considero que dicha reacción psicológica, en la cual la víctima de un secuestro pasa de repudiar la conducta de su agresor a actuar de forma complaciente ante sus actos y en los casos más extremos a justificarlos, ilustra el giro punitivo que ha vivido en líneas generales el movimiento de mujeres ${ }^{17}$ pasando de criticar fuertemente el derecho penal con el objetivo de limitarlo, a no sólo demandar la punición de conductas, sino a justificarlas, revalidando su función. Es a partir de este fenómeno que he planteado la pregunta que este artículo busca responder: ¿por qué los movimientos de mujeres demandan la punición de conductas en Colombia?

Para presentar una respuesta satisfactoria se planteó el siguiente límite temporal entre el 23 de mayo de 2013, día en la cual, una mujer fue brutalmente asesinada y violada en el Parque Nacional de Bogotá, conmocionando a la sociedad colombiana y posicionando la discusión en torno a la violencia contra la mujer en un lugar especial en el foro público ${ }^{18}$; hasta el 6 de julio de 2015, día en que entró en vigencia la Ley

15 Scherrer. S. "Limits to Criminal Law?" en Abolitionisn, Towards a non-repressive approach to crime. Van Swaaningen R./Bianchi H. (eds.). Amsterdam: Free Universitu Press, 1989; Van SwaAningen R. "Femenismus und Abolitionismus als Kritik der Kriminologie", en Kriminologisches Journal Heft (3); versión en español (trad. E. LarRauRi), "Feminismo, criminología y derecho penal- Una relación controvertida", en Papers d'Estudi i formació, (5) pp. 85-107., 1990; Calvo García, M. "The Role of Social Movements in the recognitions of gender violence as a violation of human rights: from legal reform to the lenguaje of rights". En The Age of Human Rights Journal (6) pp. 60-82. 2016.

16 Garlan, David, The Culture of Control. Oxford: Oxford University Press, 2001.

17 En este punto es necesario hacer la salvedad que es una posición que se piensa en líneas generales, pero esto no implica que sea la única. Por el contrario, la variedad de matices que alberga el movimiento de mujeres da cuenta que en sí mismo existen disensos. Sin embargo, en el marco del trabajo se hace esta generalización, admitiendo que siempre es injusta.

18 Agatón, Isabel. Si Adelita se fuera con otro. Del feminismo y otros asuntos. Bogotá D.C.: Editorial Temis, obras jurídicas. 2017. P. 158. 
172 Mujeres, atrocidad y castigo: un estudio de caso sobre las razones del movimiento de mujeres para penalizar el feminicidio en Colombia - David Fernando Cruz Gutiérrez

1761 que se conoce, en memoria a la mujer asesinada, como Ley Rosa Elvira Cely, cuya principal consecuencia jurídica es la tipificación del feminicidio como delito autónomo dentro de la legislación penal colombiana. Estos límites temporales me permiten reconstruir, a través de la técnica narrativa, desde las condiciones en las que se dio el crimen y las diferentes discusiones públicas que suscitó tal monstruoso acto hasta la sanción presidencial de la ley en cuestión.

Esta estrategia metodológica, que cabe dentro de la categoría de estudio de caso, a pesar de ser ampliamente cuestionada dentro de la investigación científica ${ }^{19}$, responde a la necesidad de registrar y estudiar la conducta de las personas involucradas en el fenómeno sujeto a estudio ${ }^{20}$. Como fuentes primarias de carácter cualitativo se eligieron las siguientes: i) cincuenta artículos periodísticos de los principales periódicos de relevancia nacional: Semana, El Tiempo, El Espectador ${ }^{21}$-y algunos internacional como la $B B C$ de Londres- publicados durante el límite temporal propuesto, de los cuales se referencian doce; ii) seis artículos de opinión en foros especializados, en donde activistas del movimiento feminista se expresaron sobre el tema, de los cuales sólo se referencian tres22; iii) La Ley Rosa Elvira Cely y su respectiva exposición de motivos; iv) el proyecto presentado al Congreso y las cuatro ponencias que se presentaron en los debates tanto en la Cámara de Representantes como en Senado de la República; v) La recomendaciones que presentó el Consejo Nacional de Política Criminal frente al proyecto; y vi) dos entrevistas semiestructuradas realizadas a dos activistas del movimiento de mujeres, entre ellas Liliana Silva Miquez perteneciente a la Casa de la Mujer y a Angélica Lozano y su asesor jurídico Iván David Márquez²3, pertenecientes al Partido Verde.

Para cada tipo de fuente se utilizaron estrategias diferentes de recolección. En el caso de los artículos periodísticos, se utilizaron dos estrategias diferentes, por un lado, se realizó una búsqueda en las bases de datos virtuales disponibles en los portales web de cada uno de los periódicos y por el otro, se revisaron las publicaciones físicas

19 Stoeker, R. "Evaluating and Rethinking the Case Study". En The Sociological Review (39). 1991; Venkatraman, N. y Grant. J.H. "Construc measurement in Organizational Strategy Research: a Critique and Proposal. En Management Review 11(1): pp. 71-87" 1986

20 Martínez, P.C. "El método de estudio de caso: estrategia metodología de la investigación científica. En Pensamiento y Gestión (No. 20). Barranquilla: Universidad del Norte.2006. pp. 17-193

21 Se escogieron estos tres periódicos por su relevancia en el contexto local, tanto por su carácter de circulación nacional como por importancia en el medio.

22 Activistas de la talla de Gloria Inés Ramírez y Olga Amparo Sánchez.

23 Esta entrevista se realizó en el marco de elección legislativa de 2018 en Colombia. Se realizó en la sede de campaña de la Angélica Lozano y Juanita Goebertus. 
correspondientes a las fechas aledañas al deceso de Rosa Elvira ${ }^{24}$. En el caso de los artículos de opinión, su búsqueda obedeció a la importancia de la autora dentro del movimiento de mujeres, tomando como criterios principales su calidad de directora de alguna entidad importante en el medio, o de su capacidad de acción política. En el caso de los documentos jurídicos, tanto la exposición de motivos como la Ley, estaban publicadas en medios virtuales, mientras que los textos para la ponencia fueron consultados en la Gaceta del Congreso. Además, para la realización de entrevista semiestructuradas se consolidaron unas guías de discusión con puntos centrales ${ }^{25}$ que permitieran darle pigmentos distintos a la investigación de los que se recolectaron en las otras fuentes.

Finalmente, el texto se organiza en seis partes distintas. Las primeras tres contextualizan la lucha del movimiento de mujeres en el escenario internacional, su espíritu crítico y sus relaciones con el derecho penal para, posteriormente, aterrizar y contextualizar la historia de dicho movimiento en el teatro local. En la parte cuatro y cinco se realiza el estudio de caso, narrando las características del crimen que se perpetró contra Rosa Elvira, la reacción del movimiento de mujeres, las acciones colectivas que tuvieron lugar y su paso por el Congreso de la Republica. En la sexta parte, se presenta el aporte teórico que corresponde a la respuesta al interrogante principal del texto. Para su mejor comprensión esta se presenta en tres niveles de profundidad distintos, el primero, siendo el más superficial describe las razones pragmáticas que soportaron la legislación del feminicidio como delito autónomo; en el segundo nivel, se presenta una lectura del crimen atroz como una oportunidad política; y en el tercer nivel, como conclusión, se presenta el aparente sincretismo ideológico entre la teoría del funcionalismo radical y la demanda de punición del movimiento de mujeres.

\section{Una insatisfactoria respuesta: el papel de los movimientos sociales en la demanda punitiva}

Arie Freiberg ${ }^{26}$ considera que en la última parte del siglo XX se produjo una ruptura en la relación entre el derecho y la sociedad, caracterizada por la aparición de rasgos

24 En el caso de las búsquedas online se utilizaron las siguientes palabras en cada uno de sus portales: Rosa Elvira Cely, Feminicidio, Crimen de Rosa, Indignación por muerte en el Parque Nacional y Secretaria de Bogotá feminicidio. Por otro lado, cuando se trató de publicaciones físicas, se buscaron las ediciones cercanas a las fechas de la Muerte de Rosa Elvira Cely, en donde se constató que en los tres casos los optaron por dedicarle su portada al caso en cuestión.

25 Especialmente: i) las aspiraciones de varías de las activistas en la tipificación del delito, ii) la imagen que tienen de sistema penal, iii) el rol que cumple el derecho penal y el castigo en la sociedad.

26 Freiberg, Arie. "Affective Versus Effective Justice: Instrumentalism and Emotionalism in Criminal Justice" en Punishment \& Society (3). Australia: University of Melbourne. 2001. 
174 Mujeres, atrocidad y castigo: un estudio de caso sobre las razones del movimiento de mujeres para penalizar el feminicidio en Colombia - David Fernando Cruz Gutiérrez

expresivos, emocionales y no racionales en el uso del derecho, que contradicen una aspiración weberiana, en la cual prima su uso racional27. Estos rasgos emocionales, argumenta Freiberg ${ }^{28}$, se manifiestan con especial fuerza en la política criminal, mostrando que el crimen y el castigo, como advierte Beckett $^{29}$, son construcciones políticas muy complejas, que acarrean una multiplicidad de significado ${ }^{30}$ y por ende, su entendimiento no se puede restringir a las prácticas que buscan disminuir el nivel criminalidad.

La academia global, en diversos contextos, ha realizado esfuerzos considerables para desentrañar los diferentes significados del crimen y el castigo ${ }^{31}$. Al respecto, T.R. Tyler \& Boeckmann ${ }^{32}$, en un estudio sobre la legislación Three Strikes and your Out ${ }^{33}$, exploran los matices psicológicos y los distintos significados del castigo en el caso del Estado de California. Para los autores, el apoyo a las medidas punitivas por parte del público tiene un vínculo directo con la representación del crimen como un daño simbólico a la sociedad, lo que supone una falta de claridad de las instituciones públicas frente al problema de la seguridad, un ataque al conjunto de valores morales compartidos socialmente por parte del delincuente y es, además, una muestra importante del debilitamiento de los vínculos sociales ${ }^{34}$. En una dirección parecida, Caton $R{ }^{35}$ resalta que lo que se proscribe penalmente entraña valores culturales y morales que simbolizan determinado estilo de vida, razón por la cual el quebrantamiento

27 Ibídem, p. 269.

28 Ibídem.

29 Beckett, Katherine. "Making Crime Pay: Law and Order in Contemporary American Politics". En Socia Forces (77) pp. 789-800.

30 Esta conclusión también parece estar ceñida a lo que argumenta HASSERMER (1995), pues la definición de lo criminal y del bien jurídico que protege esta asignación, no es únicamente una cuestión de poder e intereses, sino que también abarca la provisión, defensa y elaboración de símbolos con un alto potencial emotivo, o lo contrario, es decir, su eliminación o destrucción.

31 Por ejemplo: en Gran Bretaña y el Estados Unidos el trabajo de Garland (2001) y de Tyler \& Boeckmann (1997) resulta fundamentales; en Nueva Zelanda, el de Pratt (2003) y Friedberg (2001).

32 Tyler, T.R. y Boeckmann, R.J "Three strikes and you are out, but why? The psychology of public support for punishing rule brekers" en Law \& Soecity Review (31) 237-265, 1997.

33 La llamada Three Strikes Law fue implementada por primera vez en Estados Unidos por el departamento de Estrategia Anti- violenta, y establecía que, si una persona resultaba culpable por un delito violento muy grave y por otros dos conductas delictivas, era condenada a una pena de cadena perpetua de ahí la expresión Three Strikes and you are out.

34 Tyler, T.R y Boeckmannm, R.J. 1997, p. 240

35 Caton, Roв "Crime, punishment and the moral emotions: righteous minds and their attitudes towards punishment" en Punishment \& Society (17.) Leicester UK: Montfort University. 2015. 
de estas normas despierta emociones retributivas por parte de la sociedad ${ }^{36}$ que no pueden pasarse por alto por parte las instancias oficiales.

Garland llama a este fenómeno el "retorno de las sanciones punitivas y la justicia expresiva"37 argumentando que:

El castigo -en el sentido del castigo expresivo que trasmite el sentimiento público - es una vez más un propósito respetable, abrazado abiertamente, llegando a afectar no solo a las condenas más graves para las ofensas más serias, sino también a la justicia juvenil y las penalidades comunitarias. El lenguaje de las condenas y el castigo a retornado al discurso oficial y lo que se presenta como la «expresión del sentimiento público» a menudo se ha impuesto a los pareceres profesionales de los expertos de la penología. ${ }^{38}$

Lo anterior ha traído una serie consecuencias importantes. Por un lado, la voz de los expertos y profesionales ha perdido el monopolio sobre el campo, lo que ha impactado en la fuerte politización del proceso de formulación de políticas criminales, inclinando la balanza hacia las demandas del gran público, pues suelen beneficiar a enclaves electorales ${ }^{39}$. Parafraseando a Máximo Sozzo ${ }^{40}$ las políticas de mano dura contra la criminalidad se vuelven una necesidad política y resulta imposible construir ventaja política oponiéndose a la orientación punitiva del juego democrático ${ }^{41}$. Además, en este contexto, por la naturaleza dinámica de la democracia -y en general de la política-, se lanzan iniciativas que no están orientadas a controlar efectivamente

36 Esta posición está altamente influenciada por la sociología de Emilie Durkheim quién argumentaba que el castigo, como todo proceso moral, tiene la función de preservar los valores compartidos y las convenciones colectivas en las que se basa la vida en sociedad.

37 Garland, David, The Culture of Control. Oxford: Osford University Press, 2001. P. 42.

38 Ibídem, p. 44.

39 Bottoms, A. "The Philosophy and Politics of Punishment and Sentencing" in The Politics of Sentencing Reform, Clarkson, C y Morgan, M. (eds.). Oxford: Press, Clarendon 2000, pp. 153-216; Garland, 2001; David Garland, "On the concept of moral panic". En Crime, Media, Culture: An international Journal (4), pp. 9-30. 2008; Pratt, J., "Castigos ostentosos y emotivos: su declinación resurgimiento en la sociedad moderna" en Delito y sociedad: revista de ciencias sociales (22), pág. 35-56, 2006; J. PratT "Cultura, Emoción y Castigo Penal" en Nova Criminis (5): visiones criminológicas de la justicia penal. Pp. 53-135. 2013.

40 Sozzo, Máxımo. "populismo penal: historia, balance, dilemas y perspectivas de un concepto" en Nova Criminis II (14): visiones criminológicas de la Justicia Penal, pp. 79-129, 2017.

41 Matthews (2005), crítica fuertemente el consenso alcanzado por la criminología consistente en que se las sociedades contemporáneas entraron en una época de resurgimiento de la punitividad. Su principal argumento es que existe un foco desmedido de la criminología contemporánea que tienen a exagerar los márgenes de la punitividad contemporánea. 
176 Mujeres, atrocidad y castigo: un estudio de caso sobre las razones del movimiento de mujeres para penalizar el feminicidio en Colombia - David Fernando Cruz Gutiérrez

el fenómeno criminal sino que buscan, a través del incremento de punibilidad y la creación de nuevos tipos penales, provocar efectos simbólicos para expresar, por un lado, sentimientos públicos negativos frente a una conducta en particular y por el otro, afirmar al público que se han tomado las medidas necesarias para combatir el problema -en otras palabras, mostrar que se está haciendo algo- ${ }^{42}$. Estas acciones, en conjunto, buscan solventar la desconfianza institucional que produce en la población una alta percepción de inseguridad.

Sin perjuicio de lo anterior, como el mismo Garland ${ }^{43}$ señala, es un error focalizar toda la atención en el proceso político por cuanto, si bien es determinarte, se inscribe en un contexto más amplio, el cual permite que este tipo de prácticas resulten fructíferas para los actores políticos. En esta dirección, el papel de las víctimas ${ }^{44}$, los medios de comunicación ${ }^{45}$ y de los movimientos sociales ${ }^{46}$ resultan relevantes para explicar las condiciones de posibilidad de políticas criminales de corte punitivo.

En efecto, las víctimas de los delitos adquirieron una voz privilegiada en el foro público, sus relatos tanto auténticos como universales, le dieron un rostro al dolor y promovieron la sensación de que cualquier persona está a la merced de la criminalidad. Pronto se fortalecieron los vínculos de compasión entre las víctimas y la sociedad gracias, en gran medida, a lo que Fassan ${ }^{47}$ llama a la movilización del lenguaje del trauma, es decir, la relevancia social que tiene la movilización del cuerpo alterado, enfermo 0 violentado, y el sufrimiento, como estrategia de comunicación verba ${ }^{48}$. Este

42 Garland, 2001, p. 131 ss.

43 Ibídem.

44 Van Swanimign, R. "La política de seguridad ciudadana en Holanda. Traficando con el miedo" en Revisa española de investigación Criminológica (No. 3) pp. 1-21, 2005; Didder Fassin y R. Rechtmam, The Empire of Trauma. An inquiriti into the condition of victimhood. Oxford: Princenton University Press. 2009; Loarder, I. y Sparks, R. "The question of public criminology: seeking resources of hope for a better politics of crime" en Internacional Annals of Criminology (Vol. 52) pp. 155-177; Spark, R. Loardes, Ian y Dzur, Albert. Democratic Thepry and Mass Incarcelation. Oxford: Oxford University Press, 2016; J. Pratt y M. Mıao. "Penal populism: the end of reason" en Nova criminis: visions cirminologicas de la justice penal (no. 13) pp. 33-105. 2018; Pratt, 2006;

45 Giddens, Modernity and Self-Identity: Self and Society in the Late Modern Age. Cambridge: Cambridge Polity Press. 1991; James T. Hamilton. Channeling Violence: The Economic Market for Violent Televisión Programming. 1998; Sara Sun Beale, "The News Media's Influence on Criminal Justice Policy: How Market-Driven News Promotes Punitivesness" en 48 Wm. \& Mary L. Rev. 397, 2006.

46 Garland, 2001 Sozzo, 2017; Van Swaanigen, 1991.

47 FASSIN, 2009.

48 El viraje social que dio lugar a esta cambio está magistralmente explicado en el libro del antropólogo francés Didier Fassin the empire of trauma, en el cual argumenta que los sentimientos moralesse han 
tipo de prácticas, ha generado que el lenguaje traumático, expresado en lo que se escucha, se lee y se ve del crimen, impulsará la demanda de castigos más emotivos que reflejan la ira pública por la comisión del delito y el respaldo a la víctima ${ }^{49}$. En palabras de Garland:

El nuevo imperativo político es que las victimas deban ser protegidas; sus voces deben ser escuchadas, su memoria respetada, su ira expresada y sus miedos atendidos (..) Esta satisfacción de las víctimas también tiene a invalidar la preocupación por los delincuentes. El juego de suma cero que existe entre unos y otros asegura que cualquier demostración de compasión hacia los delincuentes, cualquier mención de sus derechos, cualquier esfuerzo por humanizar su castigo puede ser fácilmente considerado como un insulto a las víctimas 0 a sus familias..$^{50}$

A su vez, los medios de comunicación retratan el crimen de forma selectiva, concentrándose en incidentes brutales y sensacionales, y descuidos escandalosos por parte del sistema de justicia. En esta selección, como lo evidencian Hamilton ${ }^{51}$ y Sun Beale $^{52}$, entran en juego factores económicos que determinan el estilo y el contenido de la información que se publica. El crimen violento, en este contexto, se vuelve un mecanismo redituable para crear audiencias, por las distintas preocupaciones y ansiedades sociales que surgen en torno a este, lo que explica su papel preponderante en los distintos medios de comunicación. Esto ha terminado por fortalecer a los medios como agentes de control social con la capacidad de "reconocer y delimitar el problema social"53.

En línea con lo anterior, una parte importante de la literatura especializada en el tema, ha estudiado las consecuencias que tiene para la política criminal y la justicia

apoderado de la política contemporánea lo que trajo, como principal consecuencia, la articulación de un lenguaje en el ámbito político que se articula más hacia las emociones y menos hacia la razón, y qué, además, tiene altos índices de efectividad para generar apoyo en distintos sectores de la sociedad. Sin embargo, como bien lo destaca Fassin (2009) esto no siempre fue así, la política coaptada por los sentimientos morales es un fenómeno relativamente reciente, que surge a finales del siglo XX, inicialmente para manejar poblaciones e individuos que se encuentran en situaciones de inequidad y en contextos de violencia o experiencias de sufrimiento, con el objeto precisamente de aliviar esté sufrimiento.

49 Pratt \& Miao, 2018, p. 51

50 GarLAND, 2008, p. 241

51 Hamilton, 1998

52 Sun Beale, Sara 2006.

53 Fuentes Osorio, Juan L. "Los medios de comunicación y el derecho penal" en Revista Electronica de Ciencias Penal y Criminología (núm. 07-16) pp. 16-51, 2005. P. 2. 
penal el papel de los medios como agentes de control social54. Una de sus principales conclusiones es que la interacción de los medios con la justicia penal, impacta en la confianza del público sobre la capacidad que tiene el sistema para satisfacer las demandas justicia ${ }^{55}$. Al respecto, Townsend ${ }^{56}$ argumenta que cuando los medios sobre representan los crímenes violentos y muestran como indulgentes a los procedimientos judiciales que recaen sobre estos, se debilita la confianza del público y se fomentan el miedo al crimen, por un lado, y el enojo y ulterior deseo de venganza, por el otro ${ }^{57}$. Usualmente estos sentimientos ${ }^{58}$ se traducen en apoyo de la población a políticas criminales de mano dura 59 .

Por otro lado, Garland y Sozzo ${ }^{60}$, señalan que los movimientos sociales también han cumplido un rol importante como soporte de las demandas punitivas. Como afirma Garland, el desbordado protagonismo de las víctimas ha dado paso a un producto apreciado en los círculos políticos, su representación ${ }^{61}$. Lo que ha influido, no sólo desde el punto de vista de los partidos y líderes políticos, que ahora se proclaman los principales benefactores de los intereses de las víctimas, apareciendo en foros públicos y en fotos con ellas, sino que también ha influido en las estrategias y mecanismos de movilización de los movimientos sociales. En esta dirección Sozzio ${ }^{62}$ considera que, en los casos particularmente graves de criminalidad con un especial cubrimiento mediático, la representación política y mediática de la víctima, supone

54 Vea: Townsend, 2011; Richard L Fox, Robert W Van Sickel \& Thomas L Steiger, 2007; Garland, 2008.

55 Fuentes, 2005; Garland, 2008; Chirs Towsend. "Interaction Between the Media and the Criminal Justice System" En The Western Australian Jurist (193) pp. 193-232, 2011.

56 TOWNSEND, 2011.

57 Ibídem, p. 231.

58 Cabe destacar que si bien el miedo al delito y el enejo se llevan la principal atención por parte de los estudiosos, también existen otros factores como prejuicio racional, el miedo al crimen ciertas atribuciones para comportamiento criminal y la ideología política --especialmente conservadurismo político--(Johnson, 2009). Si desea profundizar vea: Johnson, 2009; Devon 2009; Garland, David 2007; VIDMAR, N. 2001.

59 Langworthy, R.H. y Whiehead, J.T. "Liberalism and fear as explanations for Punitiveness". En Criminology (24), pp. 575-591, 1986; K. Dowler. "Media consumption and public attitudes toward crime and justice: The relationship between fear of crime, punitive attitudes, and perceived police effectiveness". En Journal of Criminal Justice and Popular Culture, No. 10 pp. 109-106, 2003; Pratt, J. 2006; JoHnson, D. "Anger about crime and support for punitive criminal justice polices". En Punisment \& Society, No.11 pp. 51-66. 2009

60 Garland, 2001; Sozzo, 2017.

61 Garland, 2001, p. 241.

62 Sozzo, 2017. 
una oportunidad política en la que entran en disputa diferentes actores con agendas particulares, entre ellos los movimientos sociales.

En esta literatura, el estudio de los movimientos sociales aparece de forma superficial, siendo descritos como mecanismos de respaldo al clamor popular de políticas de mano dura que, como afirman René Van Swaaningen y Pitch ${ }^{63}$, han terminado revalidando la intervención del derecho penal en nuevos espacios. Sin embargo, aún es esquiva una apuesta teórica robusta por develar el papel de los distintos movimientos sociales en un escenario de expansión punitiva, por cuanto, el estado actual de la teoría únicamente ha explorado una parte de la respuesta, que si bien ha acreditado la influencia de los movimientos sociales en políticas criminales de mano dura particulares, deja de lado el análisis de las razones que sustentan esta decisión por parte de los activistas pertenecientes a estos movimientos. Este espectro de investigación, que parece no tener mayor relieve en el estado actual de la criminóloga crítica, nos ofrece la posibilidad de visibilizar que los movimientos sociales no son monolíticos, sino que en su seno se producen discusiones y resistencias frente al papel que debe cumplir el derecho penal en su agenda política en donde juegan distintas variables, tanto emotivas, como racionales y estratégicas.

\section{Las mujeres y el derecho penal: una engañosa tentación}

La relación entre los movimientos de mujeres y el derecho penal es compleja ${ }^{64}$. Esto se debe a que una parte importante de los esfuerzos tanto teóricos como prácticos del movimiento de mujeres dan cuenta de los diferentes puntos de vista y de los matices que tiene el derecho penal para servir a los propósitos de estos movimientos. Por un lado, una parte importante del esfuerzo teórico feminista se ha dedicado a develar cómo el sistema penal y la criminología positivista ${ }^{65}$ ha construido a la mujer como un sujeto que necesita tutela ${ }^{66}$, cuya transgresión a la ley penal sucede únicamente cuando supera los límites tradicionales del rol género que le es asignado ${ }^{67}$.

63 Van Swaaningen, 1990; T. Pitch. "La violencia contra las mujeres y sus usos políticos". En Anales de la Cátedra Francisco Suárez (48) pp. 19-29, 2014.

64 Bergalli y Boldeon, 1992.

65 Véase: Lombroso \& Ferrero (1895).

66 En una crítica general del Derecho, Mckinnon argumenta que éste se ha consolidado en razón de un código binario entre diferentes valores, en donde prevalecen unos y otros, especialmente, entre el género masculino y el femenino.

67 Ariza, Libardo y Iturralde, Manuel. "Mujer, crimen y castigo penitenciario", en Polít. crim. Vol. 12, No 24, pp. 731-753, 2017. 
180 Mujeres, atrocidad y castigo: un estudio de caso sobre las razones del movimiento de mujeres para penalizar el feminicidio en Colombia - David Fernando Cruz Gutiérrez

es decir cuando trasgrede la maternidad, el matrimonio y en general el espacio y el trabajo doméstico ${ }^{68}$. En este escenario la función del castigo era:

reconducir a la mujer a un modelo de conducta basado en la castidad y fidelidad sexual y, por otro, hacer aprender a la condenada el trabajo doméstico, considerado fundamental para absorber el rol femenino, pero además importantísimo económicamente, por cuanto que de él depende el trabajo asalariado de otros miembros de la familia. ${ }^{69}$

Por otro lado, durante finales los años 70 , en Holanda y en Italia ${ }^{70}$, grupos pequeños de mujeres empezaron a movilizarse con el objetivo de visibilizar la violencia sexual. En el caso de Holanda, la movilización social estuvo anudada a un contexto de liberación sexual por parte de las mujeres; los abusos, por ende, ya no se cometían en el ámbito de lo doméstico/privado, sino que empezaron a trasladarse a espacios de concurrencia pública, como las discotecas, permitiendo su visibilización y la toma de conciencia social ${ }^{71}$. No obstante, para el Gobierno holandés, la presión para tomar medidas sobre el tema aumentó con la publicación de un estudio de Jeanne Doomen ${ }^{72}$ en donde se mostraba que cerca de la mitad de mujeres entrevistadas había sufrido algún tipo de violencia sexual en su vida. Las cifras resultaron aterradoras para la opinión pública forzando a las autoridades a conformar una comisión para afrontar el problema. En su inicio, esta comisión recogió los principales postulados del movimiento feminista, en donde se incluía el derecho penal como parte de las medidas para enfrentar el problema, pero su lugar era marginal en el diseño de política pública. Lastimosamente, este proyecto nunca llego a convertirse en ley, pues la comisión cambió de posición y pasados unos años presentó ante el Congreso holandés un nuevo diseño de política pública, en el cuál el derecho penal y el sistema penitenciario juagaban un papel esencial para combatir la

68 Bergalli y Boldeón, 1992; Larrauri, 2008; Mckinnon, 1987.

69 Bergall y Boldeón, 1992, p. 58.

70 En Francia sucio algo parecido, especialmente impulsado por mayo de 68, sin embargo, los resultados en materia de política criminal son difusos. Si desea profundizar consulte: BérAD (2016).

71 VAn SoEST, M. "Eerste Nederlandsehulpcentrumvoorverkrachtevrou- wen opgericht" en wen opgericht, De Nieuwe Linie, 19. 1975. Van SoEST M. (1974) considera que una institución importante en la visbilización del problema de la violencia sexual en Holanda fue la primera casa de ayuda para mujeres violadas, pues sirvió, por un lado, para que el movimiento feminista se diera cuenta de la magnitud del problema, y por el otro, para a través de la experiencia con las víctimas, las activistas entendieran las condiciones en las que usualmente tiene lugar la agresión sexual.

72 Doomen, J. Verkrachting Ervaringen, vooroordelen, achtergronden. Baarn, Anthos 1976 
violencia sexual ${ }^{73}$. En aquel momento, el movimiento de mujeres consideró adecuada la centralidad del derecho penal en el proyecto.

Por su lado, en el caso italiano, el Movimiento di Liberazione delle Donne (En adelante MLD; en español Movimiento de Liberación de la mujer) cumplió un papel fundamental. Primero, porque en 1978 en Roma, presentó una encuesta en la cual el noventa y dos por ciento de las mujeres afirmó padecer o haber padeció algún tipo de violencia sexual. De nuevo, como sucedió con el caso holandés, los datos cumplieron un papel fundamental para volcar a la opinión pública a presionar al Estado por soluciones concretas. Gracias a este impulso, el movimiento de mujeres italiano se dispuso a interactuar con el parlamento para diseñar un mecanismo que permitiera visibilizar y enfrentar el problema. El primer punto de disenso surgió en torno a la conceptualización de la violación como una forma de violencia contra la persona, pues una parte del movimiento consideraba que poner el énfasis en la persona y no en la mujer, implicaba dejar de lado el contexto que explica porque las víctimas de violación son en su mayoría mujeres. No obstante, a pesar del disenso, el proyecto siguió adelante en el órgano legislativo, dejando de lado el principal objetivo de la campaña del MLD que era generar responsabilidad social más allá del juicio penal7 ${ }^{74}$. De esta forma, la legislación se centró en la responsabilidad individual, y la mujer, en vez de convertirse en un sujeto que se reivindica se convirtió en una víctima ${ }^{75}$.

En ambas experiencias, los movimientos de mujeres fueron en un principio cautos con la centralidad del derecho penal en su propuesta. Sin embargo, una vez empezaron a dialogar con los espacios institucionales, la propuesta punitivita se fortaleció. En el caso holandés, esto sucedió con la complacencia de algunas de las activistas, mientras que en el caso italiano sucedió a pesar del manifiesto disenso de la MLD. Resulta particularmente interesante que las activistas holandesas, en reflexiones posteriores, sintieran que el derecho penal en relación con la violencia sexual es una tentación engañosa por cuanto aparece, dentro de la razonabilidad punitiva que lo sustenta, como una solución eficaz para contener la violencia sexual, cuando en la práctica, la criminalización del problema restringe su posible amplitud y por ende los medios para afrontarl $0^{76}$.

73 BelJerse, U.J. y Kools, R. “iApariencias engañosas? El movimiento de mujeres holandés, la violencia contra las mujeres y el sistema penal". En Mujeres, derecho penal y criminología, Larrauri (eds) Madrid. pp. 141-166. 1994

74 Rosenberg y Seller, "Número monográfico sul movimiento feminista negli anni 70". Memoria, rivista si storia delle donne. 1987.

75 Рітсн, T. Ressponsabilità limitate, Feltrinelli, Milán. 1989.

76 Bergalli y Boldeon, 1992. p. 64; Bustos Ramírez, pareciera apoyar esta conclusión afirmando "que el sistema penal resulta un sistema de coerción del Estado para el Estado para el Estado; por eso el individuo 
182 Mujeres, atrocidad y castigo: un estudio de caso sobre las razones del movimiento de mujeres para penalizar el feminicidio en Colombia - David Fernando Cruz Gutiérrez

Esta posición de desencanto con la justicia penal parece empatar con descripciones del sistema punitivo realizadas por la criminología crítica. Por ejemplo, Hulsman ${ }^{77}$ asegura que la justicia penal "es típica y desviacionista con respecto a la forma en que se reconstruyen las realidades y es extremadamente estrecha en cuanto al tipo de reacciones que sugiere a quienes toman las decisiones"78. Sin embargo, a pesar del aparente sincretismo teórico entre ambas posturas, una parte importante de las reflexiones, tanto del movimiento de mujeres como de la criminología crítica, cayó en oídos sordos, pues una corriente del movimiento de mujeres calificada como "oficial"79 -tal como advierte Larrauri- ha optado por el punitivismo. Esto significa, por un lado, que una parte considerable del movimiento ha aceptado el derecho penal como un mecanismo importante para lograr cambios en la sociedad y por el otro, que los movimientos de mujeres han adoptado una estrategia de movilización legal que tiene como objetivo "inducir en la actividad legislativa para la creación de nuevos delitos y el endurecimiento de las penas" 80 , es decir influir en la política criminal de tal forma que se endurezcan las sanciones sobre los bienes jurídicos que consideran indispensables proteger.

Como se dijo más arriba, el primer bien jurídico sobre el que se desplegó la protección penal fue la integridad y libertad sexua ${ }^{81}$. Sin embargo, en poco tiempo, la demanda de los movimientos de mujeres, como argumenta Larrauri, centró su atención en la violencia de género, por cuanto este tipo de violencia tiene como base la desigualdad existente entre lo masculino y lo femenino -incluyendo la subordinación sexual-, que mantiene a la mujer en una posición subordinada al hombre ${ }^{82}$ lo que fomenta, a su vez, expresiones de inequidad como la discriminación y el acoso laboral, hasta expresiones de violencia directa como la violencia intrafamiliar y, en el peor de

pierde su personalidad y queda reducido sólo a ser víctima del delito o la infracción, o bien ser autor de un delito o infracción. Se institucionaliza el sistema, y en realidad ni el autor ni la víctima cuentan; [... ] y ello es lógico, pues el sistema no los considera a ellos sino únicamente al Estado" (p. VIII.).

77 Hulsman, L. Conflcitos relativos a la terminología: "Situaciones problemática" VS. "Crimen de Investigación Cientifica. Bogotá: Universidad Externado de Colombia, 2003.

$78 \quad$ Ibídem, p. 34

79 Larrauri habla de feminismo oficial por cuanto considera que una parte importante del feminismo ha sido, históricamente, reacio a acudir al Estado. LarRauRi, 2007, p. 68.

80 Paladines, Jorge Feminismo punitivo, Cuando el género se redujo al castigo. Disponible en: http:// www.rebelion. org/docs/174609.pdf, (Consulta: 1-06- 2014). 2013 p. 9

81 BeIJERSE, U.J. y KoOL, R. 1990.

82 Larrauri, 2007, p. 18 
los casos, la muerte. La apuesta, entonces, se orientó en atacar todas las conductas derivadas o conectadas con la violencia de género desde el enclave del derecho penal, buscando con el poder punitivo el enjuiciamiento y sanción a los agresores de las múltiples manifestaciones de la violencia contra la mujer. En este contexto se empiezan a consolidar medidas punitivas frente a las distintas expresiones de esta violencia. Una muestra de ello es:

el escalamiento del castigo en el caso del acoso sexual, que de ser un comportamiento reprobable, pasó a tener sanciones de tipo administrativo o civil hasta, finalmente, llegar al mundo del derecho penal, desde donde no hay retorno -prohibición de regreso- hacia un tratamiento no penal para la solución de este tipo de conflictos. ${ }^{83}$

En España, siguiendo esta tendencia, se expidió en 2008 la Ley Orgánica de Protección Integral contra la Violencia de Género ${ }^{84}$, la cual impulsó fuertes medidas de carácter punitivo contra conductas como las lesiones personales, las amenazas y las coacciones dirigidas a la mujer ${ }^{85}$. Latinoamérica, en su turno, no sólo siguió esta tendencia, sino que la incrementó, en parte gracias al alto índice de decesos producto de la violencia sistemática contra la mujer en países como México, El Salvador y Colombia, orientándola principalmente a la protección del bien jurídico de la vida de la mujer. En este esfuerzo, resulta especialmente importante el papel de la antropóloga Marcela Lagarde ${ }^{86}$ quien, influida teóricamente por el trabajo de Mary Ane Warren ${ }^{87}$ y Russell|88, calificó a las muertes de las mujeres y niñas acaecidas en el contexto

83 Paladines, 2013, p. 9

84 Si desea consultarla siga esté Link: https://www.boe.es/buscar/act.php?id=BOE-A-2004-21760

85 Calvo García, 2017, p. 61-62.

86 Lagarde, Marcela. Género y feminismo. Desarrollo humano y democracia. Madrid: horas y horas, 1996; Marcela Lagarde. "Antropologia, feminismo y Política: Violencia Feminicida y Derecho y Derechos Humanos de las Mujeres" en Retos Tenorios y Nuevas Prácticas (Bullen, Margaret (Co) \& Diez Mitegui (Co) pp. 209-238, 2008.

87 Warren, Mary Ane. "Gendercide: the implications of Sex Selection". En Totowa NJ, Rowman \& Allanheld Feminist Politics and Human Nature (viii) pp. 209. 1985; Mary Anne Warren cabe recordar que el termino feminicidio proviene lingüísticamente del inglés feminicide utilizado por los angloparlantes para describir las muertes producto de la violencia de género (Russell \& RADFoRd, 1992 \& RusselL; 2012). Sin embargo, es heredero conceptual del termino genericidio acuñado y desarrollado por Mary Anne Warren con el objetivo de describir la más alta probabilidad que tienen las mujeres de morir o sufrir mutilaciones a manos de un hombre que por enfermedades, accidentes y guerras

88 Russel, Diana H.E. Defining Feminicide, introductory speech presented to the United Nations Symposium on Femicide. New York: ONU, 2012; Diana H.E. Russel y Jill Radford. Femicide: the politics of woman killing. New York: Twayne Publishers, 1992. 
184 Mujeres, atrocidad y castigo: un estudio de caso sobre las razones del movimiento de mujeres para penalizar el feminicidio en Colombia - David Fernando Cruz Gutiérrez

violento de ciudad de Juárez $z^{89}$-denunciados a partir de 1993-, como feminicidios $^{90}$. Para Lagarde:

El feminicidio es una de las formas extremas de violencia de género está conformado por el conjunto de hechos violentos misóginos contra las mujeres que implican la violación de sus derechos humanos, atentan contra su seguridad y ponen en riesgo su vida. Culmina en el asesinato de algunas niñas y mujeres. Hay infinidad de sobrevivientes. El feminicidio se consuma porque las autoridades omisas, negligentes o coludidas con agresores, ejercen sobre las mujeres violencia institucional al obstaculizar su acceso a la justicia y con ello contribuyen a la impunidad. ${ }^{91}$

De acuerdo a Toledo ${ }^{92}$, los crímenes producidos en México se sumaron al aumento y a la brutalidad de los homicidios femeninos ocurrido en países como Guatemala y El Salvador que, además, presentaban altos índices de impunidad. De esta forma, el feminicidio no sólo significaba el resultado material de muerte de una mujer, sino que estaba anudado a la incapacidad institucional, por un lado, y la falta de voluntad política, por el otro, para enfrentar estás problemáticas. Esta carga política con la que se relaciona íntimamente la palabra, permitió su fácil expansión a distintos contextos, situaciones e hipótesis de aplicación ${ }^{93}$. No obstante, a pesar de la diseminación del concepto, el núcleo común sobre el que se asentó la demanda punitiva en Latinoamérica, es que la muerte de una mujer, cuando es motivada por el hecho de ser mujer, comprende un desvalor especial para la sociedad y, por ende, es acreedora de una protección jurídico penal particular y más fuerte que el homicidio genérico.

89 El caso de Juárez se ha convertido en el paradigma a nivel mundial de asesinatos y desaparición de las niñas y las mujeres, pues en esta ciudad fronteriza con Estados Unidos, cerca de 400 mujeres y niñas fueron encontradas muertas, y más de un centenar de ellas sufrieron mutilaciones, torturas y violencia sexual, y sus cadáveres fueron abandonados en terrenos baldíos o en desiertos que rodean la ciudad.

90 Cabe indicar que no fue la primera vez que se habló de feminicidio en Latinoamérica. Ya en el 1960 el asesinado de tres mujeres dominicanas por las fuerzas de inteligencia del mismo país había sido calificado como feminicidio por las investigadoras costarricenses Ana Carcedo y Montserrat Sargot (Ramos de Mello, 2015)

91 Lagarde. Marcela "Antropología, Feminismo y Política: Violencia Feminicida y Derechos y Derechos Humanos de las Mujeres", en Retos Tenorios y Nuevas Prácticas (Bullen, Margaret (Co) \& Diez Mitegui (Co)). Pág. 235. 2008.

92 Toledo VÁsouez, Patsıí Feminicidio, Consultoría para la Oficina en México del Alto Comisionado de las Naciones Unidas para los Derechos Humanos (Oacnudh), México D.F.: Organización de las Naciones Unidas. 2009.

93 Estudios detallados sobre el tema establecen que el término feminicidio se ha aplica a diferencias hipótesis: i) feminicidio sexual, ii) feminicidio por ocupaciones, estigmatizadas, iii) Feminicidio íntimo, iv) feminicidio no íntimo, v) feminicidio por conexión, vi) femi genocidio. Si desea profundizar en el tema vea. 


\section{El movimiento de mujeres en Colombia: la lucha por el derecho}

En este punto, es importante destacar que durante los años noventa, el movimiento de mujeres en Colombia experimentó una discontinuidad importante ${ }^{94}$. Cómo lo narra Álvarez, dichos años estuvieron marcados por un proceso de profesionalización de sectores del movimiento feminista que ampliaron su incidencia en la sociedad y dejaron de lado la radicalidad del movimiento precedente ${ }^{95}$. A su vez, las distintas organizaciones de mujeres, que en su origen se plantearon como estructuras de movilización local ${ }^{96}$, empezaron a tejer redes de movilización que pronto, por el impacto de la Constitución de 1991, se vieron atraídas por el lenguaje de los derechos ${ }^{97}$. En este momento, como lo argumentó Lehoucq y Lemaitre ${ }^{98}$, el proyecto constitucional de finales de los años 80 y principios de los años 90, sirvió como escenario para que el movimiento se reencontrara, permitiendo que sus integrantes propusieran y potenciaran nuevas formas de movilización, con un enfoque mucho más legalista.

En tal sentido, pareciera que el movimiento de mujeres encontró, después de la Constitución de 1991, las ventajas que algunos críticos moderados ${ }^{99}$ identificaron en el derecho, considerando que las categorías, principios y retórica del derecho y de la argumentación jurídica ofrecían algunas ventajas para conseguir un cambio social100. Este nuevo aire del movimiento de mujeres, orientado hacia el Estado, la legalidad y los derechos ${ }^{101}$ no pasó inadvertido por la academia legal colombiana. Al respecto

94 Lehouco, 2016; Álvares. S.E "Latin American Feminisms "Go Global": Trends of the 1990s and Challenges for the New Millennium" en Álvarez, S.E. Dagnino, E. \& Escober, A. (Eds), Cultures of Politics. Politics of Culture. Re-visioning Latin American Social Movements p.p. 293.324. 1998

95 Como lo narra Lehouco (2016) en Colombia, es posible caracterizar en olas el movimiento feminista. La segunda ola, que se encuentra después del movimiento sufragista colombiano y qué termina, con la Constitución de 1991, estuvo marcada por una radicalización de los postulados feminista y por la adscripción de sus miembros a partidos de izquierda.

96 Especialmente la Red Nacional de Mujeres y Sisma Mujer.

97 Lemaitre, 2009.

98 Lehouco, 2016; Lemaitre, 2009.

99 Se habla de críticos moderados para diferenciales de los críticos radicales influenciados por el marxismo, quienes consideraban que confiar en el derecho es la principal trama ideológica.

100 Una posición parecida se encuentra en García (2014) quién considera lo siguiente "el derecho no hace las revoluciones, más bien es lo contrario lo que ocurre: el derecho impide que las revoluciones se hagan. No obstante, puede haber usos del derecho que, bajo ciertas circunstancias produzcan cambios sociales importantes y hasta revolucionarios" (pág. 215)

101 El viraje de los movimientos de mujeres hacia el derecho hace parte de un viraje general de los movimientos sociales. Al respecto Sousa Santos ha realizado un esfuerzo argumentativo importante por explicar este viraje, encontrando que se debe, en parte importante, a desistir de una vía emancipadora socialista, tal como la sustento el marxismo. 
186 Mujeres, atrocidad y castigo: un estudio de caso sobre las razones del movimiento de mujeres para penalizar el feminicidio en Colombia - David Fernando Cruz Gutiérrez

Jaramillo, Jaramillo \& Alfonso, Guzmán \& Molano, Lemaitre \& Sandvik y Lehoucq ${ }^{102}$, han realizado considerables esfuerzos por describir y analizar las principales movilizaciones legales del movimiento de mujeres en Colombia, enfocados especialmente a la movilización legal en torno a la Ley de Cuotas ${ }^{103}$, pero también en la movilización legal y litigio estratégico para la despenalización del aborto ${ }^{104}$, y finalmente en la movilización legal a favor de las mujeres desplazadas y víctimas de la violencia ${ }^{105}$.

Esta literatura centra su mirada en la relación instrumental entre el movimiento de mujeres y el derecho, pero también es consciente que dicha relación no se puede reducir ni explicar únicamente en razón de su utilidad, por cuanto existen otros matices dentro de dicho fenómeno que muestran su complejidad. Por un lado, Lehoucq argumenta que el uso del derecho por parte del movimiento de mujeres "sirvió para producir oportunidades políticas" ${ }^{106}$. Esto significa que el uso de las herramientas jurídicas alteró el ambiente político ${ }^{107}$ aumentando las posibilidades de éxito de sus proyectos. Dos razones llevan a Lehoucq a realizar tal afirmación. Por un lado, la cercanía del movimiento de mujeres a la Asamblea Nacional Constituyente, les permitió adquirir experiencia necesaria en el cabildeo para perfilar mejor sus prácticas, lo que sería fundamental al momento de definir la estrategia legal en la Ley de Cuotas ${ }^{108}$ y, por el otro, la profesionalización del movimiento y su conocimiento, asimilación e interpretación de instrumentos jurídicos internacionales ${ }^{109}$, no sólo moldearon la imaginación política y jurídica de las activistas, sino que les dio un piso jurídico importante para sustentar

102 Jaramillo, 2005; Jaramillo y Alfonso, 2008; Guzman Rodriguez, Diana y Molano Ayala, Paola "Ley de Cuotas en Colombia: avances y retos. Diez años de la Ley 581 de 2000". Documentos de discusión Dejusticia (13), 1-67. 2012; Lemaitre, Julieta y SandviK, K.B). Shifting Frames, Vanishing Resources, and Dangerous Political Opportunities: Legal Mobilization among Displaced Women in Colombia, Law and Society Review, 49(1), pp 5-38. 2015; Lehouco, 2016 y 2017.

103 Jaramillo, 2005; Gúzman \& Molando, 2012; Lehouco, 2016, 2017

104 Jaramillo \& Alfonso, 2008

105 Lemaitre \& SandVIK, 2015

106 Lehouco, 2018, p. 8.

107 McAdam (1996) considera que el ambiente político, como concepto es útil siempre y cuando se identifiquen las siguientes variables: i) la relativa apertura del sistema político institucional ii) la estabilidad de los alineamientos de las elites que subyacen al poder estatal, iii) a presencia de aliados entre las élites y iv) la capacidad y propensión estatal para la represión (McAdAM, 1996, p. 27).

108 Jaramillo, 2005.

109 “En particular, la Declaración y Plataforma de Acción de Beijing, la Declaración y Programa de Acción de Viena, y la Convención sobre la Eliminación de todas las Formas de Discriminación contra la Mujer" (Lehouco, 2016: p. 9). 
sus demandas. En este sentido, el derecho sirvió como un factor importante para que la movilización feminista se refrescara y tomará una nueva fuerza, sin embargo, sus efectos, tal como destaca Lehoucq, van mucho más allá del énfasis en las instancias judiciales y en la adjudicación de derechos ${ }^{110}$.

La posición de Lehoucq va de la mano con una incipiente corriente de estudios de la academia anglosajona que describen la relación entre el derecho y los movimientos sociales como campos institucionales superpuestos que en su interacción ayudan a constituirse y a formarse unos a otros ${ }^{111}$. Para este grupo de teóricos, el derecho no es un sistema estable y coercitivo, sino que, por el contrario, entender el derecho implica entender las prácticas sociales en las que éste se inscribe, incluidas aquellas que se dan por fuera de las instituciones oficiales -como los tribunales- ${ }^{112}$. De esta forma, la relación entre el derecho y los movimientos sociales es de doble vida, por un lado, los movimientos sociales dan forma a la argumentación y práctica legal a través del litigio estratégico y el lobby legislativo ${ }^{113}$. Mientras que, por el otro, el uso del derecho ayuda a definir el comportamiento de los activistas frente a problemas particulares lo que permite identificar las restricciones empíricas de sus prácticas y las consecuencias de su comportamiento ${ }^{114}$.

110 Lehouco, 2017. P. 15.

111 Eldeman, Leachman y McAdams. "On Law, Organizations and Social Movements", en The Annual Review of Law and Social Science (85) pp. 655-685. 2010. p. 655

112 Eldeman, Leachman \& McAdams (2015) argumentan que esto se debe a que las organizaciones que regulan la ley tienden a ser bastante ambiguas, por lo que los movimientos sociales y las organizaciones que interactúan con la ley forman espacios propios de interpretación legal -Legal environments- en busca de ideas que les permitan establecer que significa cumplir con la ley.

113 Adriaenseen, A. y Aertsen. "Punitive attitudes: Towards an operationalization to measure individual punitivity in a multidimensional way". En European Journal of Criminology, 12, 92-112. 2015.; McAdam, D. y Sснотт, W. Organizations and movements., pp. 4-40, 2005; R. Kennedy 1989, “Martin Luther King's constitution: a legal history of the Montgomery bus boycott". Yale Law J., pp. 999-1067, 1989;

SchenelBerg. "Organizational heterogeneity and the production of new forms: Politics, social movements and mutual companies in American fire insurance, 1900-1930". Research in the Sociology of Organizations, 19, 39-89. 2002; Polleta, FrancesA “The Structural Context of Novel Rights Claims: RightsInnovation in the Southern Civil Rights Movement, 1961-1966." Law and Society Review (34): pp. 367-406., 2000. Otra forma importante en la que los movimientos sociales pueden influenciar el desarrollo legal, es a través de reforzar retórica de argumentos legales particulares que consideran favorables (Keck \& SiKkink, 1998; Lounsbury 2003, McCann 1994, Schneiberg \& Soule 2005)

114 Bourdieu, Pierre, "Elementos para una sociología del campo jurídico", en La Fuerza del Derecho (Bourdieu,Pierre \& Gunter Teubner) pp 153-216. 2000; Eldeman, Leachman \& McAndams, 2015. 
188 Mujeres, atrocidad y castigo: un estudio de caso sobre las razones del movimiento de mujeres para penalizar el feminicidio en Colombia - David Fernando Cruz Gutiérrez

Por otro lado, Lemaitre ${ }^{115}$ y García ${ }^{116}$, consideran que cuando se acude a al derecho, su uso no se puede reducir a una faceta instrumental y netamente racional, sino que, en dicha operación, inciden otros factores que entran en juego. García, en una segunda edición de su famosa tesis doctoral La eficacia simbólica del derecho, propone que el derecho tiene una incidencia social y una especial capacidad de evocar símbolos que -tal vez en la mayoría de casos-sirven para legitimar el poder, pero también abren el camino para que los movimientos sociales utilicen dichos atributos en su favor. Esta relación entre derecho y símbolo es una de las premisas fundamentales de la obra de García y también una de sus principales aportes. En el fondo, García parece insinuar que existe una relación entre el derecho y la justicia que en algunos momentos específicos puede servir de utilidad para los movimientos sociales.

Lemaitre, a su turno -influida fuertemente por los planteamientos de García ${ }^{117}$-, se pregunta por qué los activistas de derechos humanos y los movimientos sociales acuden al derecho con tanto fervor, aún a sabiendas que el derecho muchas veces es inútil 0 insuficiente ${ }^{118}$ para solucionar ciertas problemáticas complejas a las que se enfrentan. Una parte importante de la respuesta se centra en la cualidad del derecho de evocar símbolos. Para Lemaitre, el derecho como una expresión lingüística, tiene la cualidad de nombrar la realidad ordenándola en un esquema moral particular ${ }^{119}$. En el caso de las mujeres, por ejemplo, el lenguaje de los derechos humanos va atado a profundos significados morales igualitaristas que van en contra de moralidades

115 LemaitRe, 2009.

116 García Villegas, Mauricio La eficacia simbólica del derecho. Sociología del campo jurídico en América Latina. Segunda edición, debate editores. Bogotá D.C. 2014.

117 Si desea constatar la influencia de García en Lemaitre, puede revisar la introducción a la segunda edición de la Eficacia Simbólica del Derecho.

118 Al respecto el trabajo de Carol Smart (1986), argumenta que si bien las luchas feministas han utilizado el derecho como un elemento fundamental y han logrado a través de él -en algunos lugares- satisfacer algunas demandas, como la igualdad formal, los problemas y la inequidad de género persisten. Este tipo de enseñanzas a nivel global le han permitido al movimiento feminista tener claridad sobre qué papel debe darle a movilización legal y que tipo cantidad de esfuerzos, dado su potencial para construir cambios, se merece.

119 Tradicionalmente este esquema moral al que sirve al derecho es, de acuerdo a estudios como los de Mckinnon (1987) y Gillıigan \& Richards (2009), una visión patriarcal de la sociedad. Mcckinnon, (1987) por ejemplo, argumenta que el derecho se identifica con un modelo de conceptos, entendidos como ideales y asignados al género masculino, tales como racionalidad, abstracción, objetividad y poder que excluían a sus opuestos, es decir, irracionalidad, subjetividad y sensibilidad, asignados al género femenino. 
tradicionales que son, en materia de igualdad de género, patriarcales y violentos ${ }^{120}$. En este ejercicio de nombrar la realidad, el derecho se convierte en un motor de producción de la misma. En palabras de la autora:

Cuando se valora la reforma legal más allá de lo que como sociedad Ilamamos la realidad, el fetiche legal es una fantasía. En este sentido, lo que quiere decir que el fetichismo legal sea una fantasía es que aspira a definir, incluso, a producir, la realidad social, o por lo menos una realidad alternativa. Y parte de producirla se va en nombrarla (...) Redefinir la realidad está en el centro de un esfuerzo político que es también una lucha por producir otra realidad social. ${ }^{121}$

Ahora bien, frente a la relación entre el derecho penal y el movimiento de mujeres en Colombia, los trabajos de Jaramillo y Jaramillo \& Alfonso, resultan fundamentales. En el primer trabajo, Jaramillo ${ }^{122}$ realiza una crítica al derecho colombiano identificado un déficit de protección importante en sistema jurídico frente a la violencia domestica que se ejerce en contra de la mujer, resaltando que las normas penales que regulan dicho ilícito, establecen condiciones que truncan la adecuada tutela de las mujeres víctimas ${ }^{123}$. En el segundo trabajo, las autoras nos ofrecen una descripción de la estrategia de Litigio de Alto Impacto en Colombia por la Inconstitucionalidad del Aborto (LAICIA), revelando dos puntos importantes de reflexión. El primero, es que el derecho penal y "los penalistas colombianos"124, aparecen como un grupo de influencia en el cual el feminismo local no tiene injerencia; y en el segundo, es la pretensión de abordar las disposiciones penales del aborto a través de parámetros

120 Lemaitre, 2009, 198. Al respecto Chesney-Lind, MedA (1989) argumenta que tradicionalmente la violencia contra la mujer -especialmente la violación - cuando es cometida por personas cercanas no era sujeto de sanciones por parte del Estado. Este tipo de violencia era entendida como el medio por el cual los hombres dominaban a las mujeres y, al practicarla, reproducían el sistema patriarcal y las relaciones de poder que lo sustentan.

121 Lemaitre, 2009, p. 395.

122 Jaramillo, 1998.

123 Jaramillo (2008) considera que existen cinco razones para esto: i) la punibilidad de las lesiones personales está relacionada con el grado en el que afectan la salud, cuando no afectan fuertemente este bien jurídico son pasadas por alto o son consideradas como casi irrelevantes; ii) el régimen de acumulación de penas limita el impacto de denunciar el carácter reiterado del delito; iii) las normas suponen que sea la mujer la que inicie la acción ante las autoridades, exponiéndose a retaliaciones por parte del agresor/conyugue; iv) el Estado no ofrece ningún tipo de protección reforzada; y v) los jueces y funcionarios públicos desestiman la violencia domestica como interés del estado cuando ésta se ejerce con un fin legítimo.

124 Jaramillo y Alfonso, 2008, p. 234 y 267, 
190 Mujeres, atrocidad y castigo: un estudio de caso sobre las razones del movimiento de mujeres para penalizar el feminicidio en Colombia - David Fernando Cruz Gutiérrez

de interpretación constitucionales como la igualdad. Estos trabajos muestran cierta apatía del movimiento de mujeres hacia al derecho penal que puede interpretarse, incluso, en términos de desconfianza, por ser una institución, como lo resalta Gómez ${ }^{125}$, fuertemente patriarcal.

En un camino análogo, varias representantes del movimiento de mujeres comenzaron a discutir la posibilidad de reformar el estatuto penal con el objetivo de integrar al sistema punitivo normas para la sanción de formas de violencia y discriminación contra la mujer. Para el año 2006, influenciadas por el contexto internacional, especialmente por el caso mexicano, el español y por el reconocimiento de la Corte IDH de la Convención Belén Do Para, se conformó el Comité Técnico para la redacción de una propuesta legislativa con este objetivo. En dicho comité tienen lugar las primeras discusiones sobre el feminicidio ${ }^{126}$ en el escenario local. Como lo narra la activista Liliana Silva Miquez ${ }^{127}$ :

Cuando entra en el debate legislativo, hay una iniciativa que estaba coordinada por la defensoría del pueblo y algunas organizaciones y esa iniciativa es financiada por la Agencia Española de Financiación Internacional. Entonces había un clic ahí y un interés político por traer aspectos de las leyes de violencia contra las mujeres al debate colombiano. Por otro lado, había otra iniciativa y estaban las congresistas del momento en una coyuntura política importante para el país hablando de "parapolítica", estaban Martha Lucia Ramírez, Piedad Córdova, Gloria Inés Ramírez, entre las que recuerdo. En el comité redactor estaba yo, como representante de la Casa [de la mujer]. El caso es que, las congresistas se dieron en la tarea, en una muestra de diversidad política a la que no se le ha prestado la suficiente atención, por sus dificultades ideológicas, de dar un debate muy complejo. Cuando estábamos en el debate estaban tres elementos importantes de la legislación: i) qué meter el término de debates de derecho sexuales y reproductivo, ii) el

125 Jaramillo Gómez, Alejandro, Un mundo sin cárceles es posible. México: Ediciones Coyoacán. 2008.

126 En Colombia también surgió la discusión sobre cuál era la palabra más acertada para describir la situación de asesinato a la mujer por su condición de ser mujer entre feminicidio y femicidio. Si quiere ahondar vea:

127 Abogada de la Universidad Nacional de Colombia, con Maestría en la Universidad de Pennsylvania. Defensora de los derechos de las mujeres y, al momento de la entrevista, activista feminista de la Casa de la Mujer. desde donde representó a mujeres víctimas en procesos judiciales, asesoró proyectos de ley y participó en acciones de incidencia con cuerpos nacionales e internacionales. En representación de la Casa de la Mujer y la Ruta Pacifica de las Mujeres hizo parte del comité técnico que discutió y redactó la Ley 1257 de 2008. 
reconocimiento del conflicto armado para la ley de violencia, que se sacó de una forma positiva y iii) el tema del feminicidio que no fue, en ese momento, un debate grande. Las Congresista no querían que fuera un delito autónomo y para nosotras en ese momento esto no era importante. ${ }^{128}$

Como resultado de estos esfuerzos, se expidió la Ley 1257 de 2008 que integraba distintos mecanismos de sensibilización, prevención y sanción de formas de violencia y discriminación contra la mujer. En el campo penal, la principal consecuencia de esta legislación fue la inclusión de un nuevo agravante al delito de homicidio en caso que éste se cometiera por el hecho de ser mujer. Sin embargo, en la práctica, los abogados y fiscales aplicaban el agravante o para todos los casos en que una mujer fuera víctima de un homicidio o no lo aplicaban en ninguno, a pesar que tuvieran el acervo probatorio suficiente para sustentar esta pretensión. Este fenómeno del todo o nada, llevó a pensar que la apuesta del movimiento de mujeres condensada en la Ley no se estaba cumpliendo $y$, por ende, una parte importante de las activistas consideraron necesario la construcción de un manual de aplicación que dotara a los fiscales de los criterios suficientes para aplicar correctamente el agravante. Sin embargo, este proyecto por dificultades presupuestales nunca se llevó a cabo.

En estos primeros acercamientos del movimiento feminista con el derecho penal, subyace una posición, en la cual la dogmática penal es "una herramienta que puede ayudar a disminuir la brecha de desigualdad cuando se la pone al servicio de colectivos históricamente discriminados"129. En cierto modo, como advierte Bergalli \& Boldeón ${ }^{130}$, parece lógico que el movimiento de mujeres quiera participar activamente en la política criminal, especialmente en contextos de altos incides de violencia de género. Sin embargo, resulta importante entender e interrogar los motivos que orientan este viraje, pues detrás de ellos se encuentran nociones del poder punitivo y su fundamento que pueden resultar, no sólo contradictorias para el espíritu crítico del movimiento feminista, sino peligrosas, por cuanto, como advierte Baratta ${ }^{131}$ no se puede construir una política de transformación de la realidad o un proyecto político alternativo y autónomo

128 L. SILva, entrevista personal, 7 de febrero de 2018.

129 Correa, Camila, Legítima defensa en situaciones sin confrontación: la muerte del tirano de casa. Bogotá D.C.: Ediciones Uniandes. 2017. P. 29.

130 Bergall y Boldeón, 1992.

131 Baratta, Alexandro. Criminología Crítica y Crítica del Derecho Penal. Introducción a la sociología jurídico penal. Buenos Aires: Siglo Veintiuno editores. 1982. 
192 Mujeres, atrocidad y castigo: un estudio de caso sobre las razones del movimiento de mujeres para penalizar el feminicidio en Colombia - David Fernando Cruz Gutiérrez

que considere al derecho penal como un instrumento impulsor pues su fin es "conservar y reproducir la sociedad existente"132.

\section{La atrocidad: el caso de Rosa Elvira Cely}

Rosa Elvira Cely murió en el Hospital Santa Clara, cuatro días después de ser encontrada en el Parque Nacional de Bogotá violada y torturada ${ }^{133}$. Lamentablemente, tanto la Policía Nacional como la ayuda médica respondieron casi 24 horas después de las llamadas de auxilio que Rosa desesperadamente realizó. A pesar de su demora, la encontraron aún con vida y consciente, razón por la cual Rosa alcanzó a narrarle parte de su calvario a los paramédicos y policías que prestaron los primeros auxilios. En aquel fatídico momento Rosa dio las pistas suficientes a la policía para encontrar a Javier Velasco Valenzuela, su tristemente célebre victimario ${ }^{134}$. Lastimosamente, estas también serían sus últimas palabras, pues al llegar al Hospital, sufriría un ataque cardíaco que le quitaría su habilidad para hablar.

El estado en el que la encontraron fue atroz. La revista Semana en un artículo dedicado a este crimen describió la escena de la siguiente forma:

Estaba tendida sobre un charco de sangre, con las extremidades inferiores desnudas y laceraciones en los brazos y en torno al cuello que sugerían un intento de estrangulamiento. En la cabeza tenía un golpe. Pero además padecía graves heridas en las zonas íntimas, donde sangraba. ${ }^{135}$

La escena fue tan bestial que, tal como lo explico el subdirector del cuerpo médico encargado de su atención, Dr. José Páramo, “los galenos de urgencias nunca habían visto algo tan brutal y tan horrible como lo que encontramos con esta persona "136. Uno

132 Ibidem, p. 239. Por la calidad de la cita me vi en la necesidad de trascribirla completa en este espacio:" La función natural del sistema penal es conservar y reproducir la realidad social existente. Una política de transformación de esta realidad, una estrategia alternativa basada en la afirmación de valores y de garantías constitucionales, un proyecto político alternativo y autónomo de los sectores populares, no puede sin embargo considerar el derecho penal como un frente avanzado, como un instrumento propulsor. Por el contrario, el derecho penal queda en un triple sentido reducido a una actitud de defensa" (BARATTA, 1982: p.239).

133 Así aparecen en reportajes del El Espectador y Semana, ambos en el 2012.

134 El Espectador. Asíactuó el asesino de Rosa Elvira Cely. Bogotá D.C.: El Espectador: Recuperado de: https:// www.elespectador.com/noticias/judicial/asi-actuo-el-asesino-de-rosa-elvira-cely-articulo-350122. 2012a

135 Semana (2012). La muerte de Rosa Elvira Cely, un crimen abominable. Bogotá D.C.: Revista Semana, Recuperado de: http://www.semana.com/nacion/articulo/la-muerte-rosa-elvira-cely-crimenabominable/258867-3// 2012.

136 Ibídem. 
de los hallazgos más terribles se dio después del paro cardíaco que le quitó el habla y obligó a los médicos a trasladarla rápidamente al quirófano. Inmediatamente, se procedió a revisar su cuerpo, encontrando, horrorizados, que tenía la pelvis y el útero rotos, pues le habían introducido un palo por el ano. Al parecer, el victimario, como corolario de su actuación, emuló un acto de empalamiento ${ }^{137}$ e introdujo una rama por su recto, lo que causaría infecciones internas que anudadas al golpe que recibió en su cabeza, culminarían en su muerte.

La atrocidad del crimen dio paso a una gigante indignación. Sin embargo, el revuelo inicial cogería impulso gracias a las acciones de un grupo de "mujeres indignadas, tristes y comprometidas con las luchas de género"138.Pronto, varias organizaciones de mujeres se sumaron y articularon para realizar marchas en Bogotá y en otras ciudades del país, con la consigna de "ni una mujer más violentada"139. En Bogotá la marcha partiría del Parque Nacional, en donde se rendiría un sentido homenaje a Rosa cubriendo el lugar en donde su victimario la postró, sometió e hirió de muerte con claveles, rosas y mensajes, tanto de animo a la familia de la víctima como de repudio al crimen. Este tipo de acciones llamaron la atención de los medios masivos de comunicación, quienes reprodujeron masiva y rápidamente el crimen, acrecentando los rasgos macabros y psicóticos del hecho.

El énfasis en las desviaciones psiquiátricas del victimario y el carácter atroz del crimen, orientó la discusión pública en torno a la efectividad de la Policía y la Fiscalía para enfrentar el accionar de este tipo de criminales anormales, favoreciendo la representación del crimen como un acto anormal que solo es el producto de una mente depravada en la que no es posible buscar ningún atisbo de racionalidad convirtiéndolo, finalmente, en un monstruo. Esta metamorfosis que despojó de la condición humana a Velasco Valenzuela para presentarlo como una bestia monstruosa, en razón del crimen que perpetró, trajo de nuevo una cuestión presente desde el siglo XIX en el análisis de este tipo de actos - monstruosos- y sus autores, concerniente a la concepción de un individuo peligroso y el problema subyacente de qué hacer con él en un sistema

137 Cabe anotar que empalamiento o empalizada, es un método de violencia contra la mujer que se utilizó de forma sistemática en la edad media para matar mujeres infieles. Y que, como lo denuncia Isabel Argon (2017) y algunos apartes de los informes del Centro Nacional de Memoria Histórica, fue también utilizado en el marco del conflicto armado en Colombia.

138 Semana. Repudio por el crimen de Rosa Elvira Cely: iNi una Rosa más!, Por Karen Racines Arévalo. Bogotá, Revista Semana. Recuperado de: http://www.semana.com/nacion/articulo/repudio-crimenrosa-elvira-cely-ni-rosa-mas/258953-3// 2012b.

139 El Espectador, 2012 a; BBC. La brutal violación que pone a marchar a Colombia. Bogotá D.C.: Recuperado de: http://www.bbc.com// 2012. 
194 Mujeres, atrocidad y castigo: un estudio de caso sobre las razones del movimiento de mujeres para penalizar el feminicidio en Colombia - David Fernando Cruz Gutiérrez

penal que, por un lado, reconoce como regla general la responsabilidad ${ }^{140}$ penal en virtud de los actos y no en razón de una condición y, por el otro, de un estatuto medico psiquiátrico que, como auxiliar de la justicia, no es capaz de conferir un significado médico a este tipo de actos.

El carácter monstruoso del crimen anudado a la ausencia de una explicación racional, produjo un sentimiento de perplejidad en la sociedad que clamaba, no sólo por la imposición de un pena significativa que neutralizara al victimario ${ }^{141}$, sino por medidas para evitar la comisión de actos de este escozor. Lo que obligó a que Eduardo Montealegre, el Fiscal General de la Nación de aquel momento, se pronunciara anunciando que crearía una Unidad de Reacción Inmediata para este tipo de crímenes. Paradójicamente, esta máscara de monstruosidad con la que se cubrió el crimen, marcó una distancia entre la sociedad y el victimario, dejando de lado la discusión y reflexión pública sobre los marcos de actuación e imaginarios sociales que acrecientan, permiten y muchas veces ocultan formas y expresiones de violencia menos atroces contra las mujeres.

En este punto, fueron los movimientos de mujeres quienes advirtieron que la máscara de la monstruosidad, como una forma para abordar el problema de la violencia de género, supone un límite para entender la magnitud del fenómeno, pues únicamente es capaz de proyectar la violencia como un producto de lo anormal; cuando para entender el problema - de la violencia contra la mujer- tenemos que partir de los espacios ordinarios y normalizados, en donde las formas de interacción social reproducen patrones de dominación del hombre hacia la mujer ${ }^{142}$. Una de las

140 Se habla de regla general, puesto que, bajo ciertas condiciones, es posible establecer responsabilidad penal por omisión.

141 Javier Velasco sería condenado a 48 años de prisión. Sin embargo, más allá de la pena impuesta a este victimario, este tipo de crímenes ha avivado la discusión sobre si es admisible jurídicamente y deseable política, social y moralmente, la imposición de la pena capital o pena de muerte para ciertos delitos, especialmente el acceso carnal violento en menor de edad. Discusión que tomaría aíre con el caso de Yuliana Samboní. Si desea profundizar sobre tema revise: https://www.elespectador. com/noticias/judicial/lastimosamente-en-el-pais-no-existe-la-pena-de-muerte-padre-de-yulianasamboni-articulo-686885

142 Este argumento, por ejemplo, es esgrimido por Bourdieu quien afirma que el proceso de dominación masculina tiene como inicio la organización social con base en la diferencia de capacidad entre el cuerpo masculino y el femenino, relegando a la mujer a un escenario doméstico, en donde se construye una violencia simbólica por la desigualdad en la forma como se relacionan ambos géneros (BouRdieu, 2000). Sin embargo, esta discusión no está resuelta en la literatura feminista y es posible encontrar diferentes puntos de conflicto y posiciones al respecto: por ejemplo, en relación al conflicto armado, una postura argumenta que dicho contexto propicia la incidencia de la violencia sexual, mientras que otra postura, argumenta que la violencia sexual es normalizada, incluso en condiciones de "paz", (Mirar los autores) 
prácticas para visibilizar estos patrones de dominación es a partir de la metáfora del cuerpo femenino "como un territorio colonizado, atravesado (...) y sometido a prácticas de restricción, abuso y poder"143 por parte del cuerpo masculino. Metáfora que lastimosamente se materializa en el cuerpo atravesado de Rosa Elvira, cuerpo que pasa de simbolizar únicamente un acto de monstruosidad, a convertirse en un reclamo que demanda la visibilidad de otras violencias menos atroces, pero más frecuentes dirigidas contra las mujeres. En evidencia de esto, Olga Amparo Sánchez afirmó:

En lo cotidiano hay otros casos tan aberrantes como este, mujeres a las que descuartizan y las dejan tiradas en el campo o las tiran al río (...) El horroroso crimen cometido contra Rosa Elvira es como el resumen de los múltiples crímenes que se cometen en el este país contra las mujeres. ${ }^{144}$

Uno de los primeros mecanismos para evidenciar este reclamo fue la introducción al contexto colombiano del término feminicidio ${ }^{145}$. Una palabra que para ese entonces no tenía la relevancia jurídica que ahora tiene, ni mucha difusión por fuera de ámbitos académicos, de activismo por los derechos humanos y de círculos feministas ${ }^{146}$, pero que pronto por su impacto semántico se empezó a diseminar en la opinión pública ${ }^{147}$. En gran parte, porque el término implica un criterio de diferenciación del cuerpo femenino sobre el que recaen formas de violencia vinculadas a la dominación masculina, convirtiéndolo, a su vez, en una forma de reconocimiento y en un mecanismo de re significación lingüística ${ }^{148}$ de la realidad ${ }^{149}$. De esta forma, la muerte de una mujer por el hecho de ser mujer, pasa de entenderse como un homicidio, categoría que homogeniza la violencia que recae sobre el cuerpo femenino y el masculino, para convertirse en

143 Múnevar. D. I. "Delito de feminicidio. Muerte violenta de mujeres por razones de género". Estudios Socio-jurídicos [S.I. ](v. 14) pp. 135-174. 2012. 0. 141-142.

144 BBC, 2016-

145 En Estados Unidos, por ejemplo, el termino feminicide ha servido como un mecanismo de reconocimiento de la violencia contra la mujer que "han nombrado de manera directa una realidad vivida históricamente por las mujeres y han fomentado las denuncias; por lo tanto, los Estados han tenido que reconocer que no son hechos aislados o íntimos ocurridos en la familia o en las relaciones de pareja", Múnevar, 2012: 166.

146 Una muestra de esto, es la forma como se cubre la noticia por los principales medios de comunicación, tanto escrita, como radial y televisada. Si desea revisarlos, vaya a i) medios escritos::,ii) radiales ; y iii) televisivos:

147 Semana, Rompiendo el silencio. Bogotá D.C.: Revista Semana, recuperado de: http://www.semana. com/nacion/articulo/rompiendo-silencio/326360// 2012c.

148 Si desea ahondar en los mecanismos de resignificación lingüística vea Amorós CelıA, 2002.

149 Amorós, Celı. "Movimientos feministas y resignificaciones lingüísticas". Quaderns de Filosofia i Ciència (30-31) pp. 7-21. p. 2002 
196 Mujeres, atrocidad y castigo: un estudio de caso sobre las razones del movimiento de mujeres para penalizar el feminicidio en Colombia - David Fernando Cruz Gutiérrez

un feminicidio, término que encarna la peor consecuencia de la colonización sobre el cuerpo de la mujer que no es nada menos que despojarla de su vida.

El uso del feminicidio como un mecanismo de re significación lingüística aparece con fuerza con posterioridad al asesinado de Rosa. La Corporación Sisma Mujer ${ }^{150}$ en el 2013, por ejemplo, publicó dos documentos que giran en torno al concepto de feminicidio, titulados Análisis de caso sobre acoso sexual y feminicidio ${ }^{151}$ y Sistematización de casos sobre acosos sexual y feminicidio ${ }^{152}$, en donde el término funciona como una represa que, entre los altos índices de violencia de la sociedad colombiana, retiene de forma especial la que está dirigida contra las mujeres, visibilizándola y exigiendo, además, una respuesta del Estado que vaya más allá del reconocimiento y repudio público de estos actos. En palabras de la Corporación:

El uso y aplicación del término de feminicidio permite, por el contrario, una lectura cualificada de estos hechos cotidianos, que permite a las autoridades investigar y sancionar a los responsables conforme a la gravedad de la conducta y adoptar políticas estatales ajustadas a la realidad y sentido del problema (...) Se trata de una relectura de los asesinatos de mujeres por el hecho de serlo, para lo cual es necesario, abandonar el lenguaje discriminante que describe los hechos como crímenes pasionales, y dejar de lado las justificaciones socio culturales dadas usualmente por la sociedad u la justicia. 153

De esta forma, el feminicidio se convirtió en la bandera de un reclamo que pronto, por la tradición del movimiento feminista colombiano del uso del derecho ${ }^{154}$, se encausó en aspiraciones legislativas. En este punto, cabe afirmar que la violencia contra la mujer dejó de ser una preocupación exclusiva de feministas y de diferentes organizaciones activistas de derechos humanos; lo que permitió que se cuestionara -y aún se cuestionen- estructuras sociales que otrora pasaban desapercibidas como factores que potencian la violencia contra la mujer en diferentes espacios de la sociedad $d^{155}$.

150 Explicar el papel de esta organización

151 Si desea consultar el documento, se encuentra en este link: http://www.sismamujer.org/wp-content/ uploads/2016/12/01.2013.An\%C3\%A1lisis-de-Casos-sobre-Acoso-Sexual-y-Feminicidio-2013.pdf

152 Si desea consultar el documento, se encuentra en este link: http://www.sismamujer.org/wp-content/ uploads/2016/11/26-An\%C3\%A1lisis-de-caso-sobre-acoso-sexual-y-feminicidio-COMPLET0-2.pdf

153 Sisma Mujer, Análisis de caso sobre acoso sexual y feminicidio. Bogotá D.C.: Sisma mujer. Recuperado de: http://www.sismamujer.org/wpcontent/uploads/2016/12/01.2013.An\%C3\%A1lisis-de-Casossobre-Acoso-Sexual-y-Feminicidio-2013.pdf// 2013, p. 4

154 Jaramillo, 2005; Lemaitre, 2009; Lehouco, 2016.

155 Existen distintas evidencias desde otros puntos de acción social que muestran que el feminicidio dejó de ser una preocupación exclusiva del movimiento de mujeres, para convertirse en un 
La puesta en escena del problema de la violencia - extrema- contra la mujer, anudada a su amplio cubrimiento mediático, abrió una baraja de posibilidades para la acción colectiva del movimiento de mujeres, diferente de otros casos de movilización legal ${ }^{156}$. Sin embargo, a pesar de la apertura de un campo de oportunidades, la movilización se centró en la reforma penal, persiguiendo la creación del feminicidio como delito autónomo.

\section{La respuesta punitiva: del proyecto 107 de 2012 a la Ley Rosa Elvira Cely}

Para finales del 2012 e inicios del 2013 la sociedad colombiana se enfrentó a uno de sus muchos fantasmas: la violencia contra la mujer. La atrocidad del crimen perpetrado contra Rosa Elvira Cely abrió la puerta a una discusión mucho mayor que giró en torno a los mecanismos legales idóneos para afrontar la terrible magnitud del fenómeno. La discusión tuvo un lugar preferente en el foro público, propiciando la intervención de expertos en violencia de género, lideresas del movimiento de mujeres y funcionarios públicos. Por un lado, Miquel Llorente, experto en violencia de género ${ }^{157}$, resume en una de sus declaraciones, una posición importante en el marco de esta discusión:

La solución de la violencia de género y violencia contra las mujeres tiene su raíz en la cultura, eso significa, que tenemos que cambiar la cultura (...)

Acabar con la violencia de género no lo va a conseguir ninguna ley. Lo va a conseguir la sociedad, pero el Estado y las instituciones tienen que ayudar a la sociedad a acabar con esa violencia. ${ }^{158}$

Por otro lado, varias lideresas del movimiento de mujeres intervinieron en la discusión pública, argumentando que el feminicidio puede convertirse en un instrumento importante, en el marco de la actuación del Estado contra la violencia de género, que permite "desarticular sistemas de creencias que naturalizan las violencias y revelan el carácter eminentemente político del asesinato de mujeres como un producto de las relaciones de poder entre los varones y las mujeres"159. En consecuencia, una reforma

156 Especialmente el caso de la ley de Cuotas. Si desea profundizar vea LeHouco (2016).

157 El Pais. Experto en violencia de género alienta a Colombia a romper con la impunidad. Bogotá D.C.: Recuperado de: http://www.elpais.com.co/judicial/experto-en-violencia-de-genero-alienta-a-colombiaa-romper-con-la-impunidad.html// 2013.

158 El Universal. La violencia de género no la acabara ninguna ley. Cali: El Universal. Recuperado de: http://www.eluniversal.com.co/cartagena/nacional/la-violencia-de-genero-no-la-acabara-ningunaley-experto-110715. 2013.

159 Ibídem. 
198 Mujeres, atrocidad y castigo: un estudio de caso sobre las razones del movimiento de mujeres para penalizar el feminicidio en Colombia - David Fernando Cruz Gutiérrez

al estatuto penal que integre como un delito autónomo la conducta de matar de forma dolosa a una mujer por el hecho de ser mujer, es deseable por cuanto implica otro paso en la construcción de "sanciones para disuadir a los victimarios y construir simbólicos y prácticas que desnaturalicen la violencia en su contra"160.

A pesar que ambas posiciones no son mutuamente excluyentes, este trabajo hace énfasis en la segunda, por cuanto la pretensión de construir símbolos y prácticas desde el derecho penal, se materializaría posteriormente en el Proyecto de Ley No 107 de 2013, por el cual se crea el tipo penal de feminicidio como delito autónomo y se dictan otras disipaciones ${ }^{161}$. Este proyecto fue radicado el primero de agosto de 2013 por señora Gloria Inés Ramírez ${ }^{162}$-en ese momento senadora de la República-, quien, en vista de la ocasión ${ }^{163}$, expresó:

con un grupo de mujeres juristas del Centro de Investigación en Justicia y Estudios Críticos del Derecho (CiJusticia ${ }^{164}$ ) y profesionales de mi unidad de trabajo legislativo, decidimos emprender la rigurosa tarea de elaborar un proyecto de ley que, aparte de contribuir a la prevención de la violencia contra la mujer por el hecho de serlo, estableciera unos criterios claros y precisos en la definición y calificación de una conducta punitiva, que por su sistematicidad, grado, crueldad, violencia excesiva y premeditación, compele a la sociedad colombiana y a sus instituciones jurídico- políticas,

160 Ibídem.

$161 \mathrm{Si}$ desea consultar el proyecto original mirar: http://www.imprenta.gov.co/gacetap/gaceta. mostrar_documento? _ tipo $=05 \& p$ _ numero $=107 \& p_{\text {_ }}$ consec $=37667$

162 Gloria Inés Ramírez es Licenciada en física y matemáticas de la Universidad Tecnológica de Pereira Magister en desarrollo social y educación de la Universidad Pedagógica Nacional Especialista en garantía de derechos laborales de la Universidad de Toledo - España Diplomado en economía, política social y género de la Pontificia Universidad Javeriana Conferencista internacional en temas educativos y de género. Se desempeñó como Congresista de la República como parte del Partido Polo Democrático Alternativo, desde el 2006 hasta el 2014.

163 En esta misma comunicación, la Senadora expresó: "La iniciativa ha contado con el respaldo de destacadas integrantes de la Comisión Legal para la Equidad de la Mujer del Congreso de Colombia, de muchas organizaciones del movimiento social de mujeres del país, y muy especialmente de las víctimas sobrevivientes, esperando contar con la aquiescencia de todas las bancadas congresionales, el apoyo de ONU Mujeres Colombia y de organizaciones defensoras de derechos humanos, a nivel nacional e internacional, dado el impacto social que ha tenido en los últimos tiempos esta nueva forma de violencia contra las mujeres, por la razón de serlo, como lo es la violencia feminicida" (Gloría Inés Ramírez 2013)

164 En el grupo de trabajo de Cijusticia estaba Isabel Argol, quién posteriormente escribiría un libro publicado en el 2017 explicando parte importante de las razones para el feminicidio en Colombia, con el nombre de Si Adelita se fuera con otro. Del feminicidio y otros asuntos. 
a la adopción de medidas contundentes que impidan hechos tan execrables como el crimen perpetrado contra Rosa Elvira Cely y contra tantas otras mujeres, cuyas vidas y cuyos cuerpos han sido hollados por una violencia infame e intolerable, que podemos calificar como feminicida, se repita. ${ }^{165}$

Adicionalmente, en la exposición de motivos de dicho proyecto, se argumenta que la iniciativa busca propiciar un cambio de paradigma en el derecho penal colombiano orientado a la protección los derechos de la mujer. Argumentando que en Colombia existe un vacío legal frente a la legislación adecuada de un delito que condense el desvalor especial de asesinar de forma dolosa a una mujer por el simple hecho de ser mujer y esta ausencia, a su vez, implica la negación de la gravedad y naturaleza política de la violencia, de la que las mujeres, lastimosamente, son víctimas. En palabras de la exposición de motivos:

En el Estatuto Penal colombiano existe un vacío en la tipificación adecuada de esta conducta, en el análisis del contexto y la valoración justipreciada de las pruebas, razón por la cual se oculta el feminicidio como una conducta punitiva que niega la violencia sistemática y persistente de que son objeto las mujeres por el hecho de serlo, lo que compele al Sistema Penal y a sus operadores, a la necesidad de reconocer su gravedad por el continuum de violencias que lo genera, para de esa forma contribuir al proceso de construcción de una genealogía de las mujeres en materia penal. ${ }^{166}$

Posteriormente al radicado, varias representantes ${ }^{167}$ de la Cámara en comunicación escrita al Secretario del Congreso ${ }^{168}$, afirmaron que el tema del proyecto es de su especial interés y respeto, razón por la cual, con previa autorización de Gloria Inés Ramírez, figuran como coautoras del proyecto. De esta forma, en el posterior trámite legislativo, aparecieron como coautoras la citada congresista, y otras cuatro representantes que a su vez formaban una importante coalición política integrada por fuerzas políticamente disimiles entre sí, como el Polo Democrático Alternativo de centro-izquierda, el Partido

165 Gloria Inés Ramírez radica proyecto de ley para tipificar el femincidio como delito. Bogotá D.C.: Prensa-Senado. Recuperado de: http://www.senado.gov.co/historia/item/14496-senadora-gloriaines-ramirez-radica-proyecto-de-ley-para-tipificar-el-feminicidio-como-delito.

166 Ibídem, pág. 8

167 Las representantes son: Rosmery Martínez Rosales por el departamento de Tolima y perteneciente al partido de Cambio Radical; Nancy Denise Castillo García por el departamento del Valle del Cauca, perteneciente al partido Liberal; Marcela Amaya por el departamento del Meta, perteneciente al partido de la Unidad Nacional; y Sandra Elena Villadiego Villadiego, por el departamento de Bolívar, perteneciente al partico de la Unidad Nacional.

168 En aquel momento Gregorio Eljach Pacheco. 
200 Mujeres, atrocidad y castigo: un estudio de caso sobre las razones del movimiento de mujeres para penalizar el feminicidio en Colombia - David Fernando Cruz Gutiérrez

Cambio Radical de derecha y el Partido de la Unidad Nacional de centro-derecha, con el objetivo de dar trámite al proyecto de ley de forma más eficiente ${ }^{169}$.

La ponencia para el primer debate se publicó el 23 de octubre de 2013 a cargo de la senadora Doris Clemencia Vega Quiroz ${ }^{170}$, qué resultaría aprobada por unanimidad ${ }^{171}$ en la Comisión Primera del Senado el 12 de diciembre del mismo año. Al día siguiente de esta votación, el Departamento Nacional de Planeación (DPN) enviaría a la senadora Gloría Inés Ramírez un concepto institucional ${ }^{172}$ en el cual recomendó modificar el proyecto en dos sentidos. Primero, que derogara el numeral 11 del artículo 103 del Código Penal que establecía un agravante punitivo, en caso de violencia de género, al delito de Homicidio por cuanto generaría una duplicidad normativa; y segundo, aplicar a otros tipos penales que pueden ser considerados, a la luz de los tratados y estándares internacionales, como agresiones con un componente de violencia de género, -tales como las lesiones personales, el acceso carnal violento, la tortura, el secuestro y la desaparición forzada- los agravantes y reglas de aplicación para beneficios administrativos y mecanismos sustitutivos contemplados en el proyecto para el feminicidio, por cuanto supondría un esquema de protección para la mujer más amplio y consistente.

El texto para la ponencia del segundo debate fue publicado el 27 de mayo de 2014, recogiendo las modificaciones formuladas por el DPN ${ }^{173}$, el cual, resultó aprobado también por unanimidad durante el segundo debate. Sin embargo, la ponencia para el tercer debate ${ }^{174}$, publicada el 26 de agosto del mismo año, recibiría, por parte del Consejo Superior de Política Criminal ${ }^{175}$ (en adelante CSPC), el 11 de noviembre, un concepto previó a su discusión el cual se expresó lo siguiente:

169 Esto mismo pasó durante el trámite legislativo de la Ley1257 de 2008, pues como lo narra L. Silva (2018), la bancada de mujeres, en un acto de colaboración política pocas veces visto entre posturas disimiles, se unieron para promover está legislación.

170 En aquel momento senadora del Partido Político Opción Ciudadana.

171 De acuerdo a las cifras de Congreso Visible hubo cuatro abstenciones y dieciocho votos positivos.

172 Si desea consultarlo mirar: http://www.imprenta.gov.co/gacetap/gaceta.mostrar_documento?p _ tipo $=2038 \& p_{\text {_ numero }}=107 \& p_{\text {_ }}$ consec $=38645$.

173 Los Ponentes para el segundo debate fueron Luis Carlos Avellaneda Tarazona por el Polo Democrático, Juan Manuel Corzo Román por el Partido Conservador, Jorge Eduardo Londoño Ulloa por Alianza Verde y repetiría Doris Clemencia Vargas Quiroz.

174 Los ponentes del tercer debate fueron María Fernanda Cabal por el partido del Centro Democrático, Harry Giovanny González por el partido Liberal, Angélica Iozano Correa por el partido Alianza Verde y Clara Leticia Rojas por el Partido Liberal.

175 Consejo Perteneciente al Ministerio de Justicia. 
La redacción de la propuesta legislativa vulnera los principios de legalidad, taxatividad, tipicidad y que de quererse incluir la conducta de feminicidio de manera autónoma, la misma debería reformularse, pues, tal como se consagra, se incluyen conductas ajenas a la violencia de género, reduce la pena, elimina una causal de agravación para las lesiones personales reduciendo el ámbito de protección penal y dificulta su aplicación (...) La regulación propuesta está llamada a cumplir con una función simbólica, que no propone una respuesta eficiente a la violencia contra la mujer, enfocándose única y exclusivamente en la violencia cuando de la misma se desprenda la muerte. ${ }^{176}$

Por lo anterior el CSPC propuso cambiar el proyecto en cinco sentidos. Primero, precisar el contenido de la discriminación, que estaba planteada de forma general, para limitarla a la discriminación de género, y así no generar confusión sobre la motivación misógina que fundamenta la tipificación del delito ${ }^{177}$; segundo, la configuración del delito de feminicidio intimo - esto es la muerte de una mujer por su condición de mujer en el marco de una relación íntima, familiar o de convivencia- debe modificarse por cuanto, de la redacción del proyecto, se induce que cualquier asesinato de una mujer inmerso en una relación íntima sería feminicidio, sin distinguir el contenido de motivación misógina propio del delito; tercero, ajustar la punibilidad de la conducta por cuanto desconoce la reforma al Código Penal por medio de la Ley 890 de 2004778, con la cual resulta más alta la pena en el homicidio agravado por la condición de ser mujer que la pena contemplada en el proyecto para el feminicidio; cuarto, el proyecto resulta reiterativo frente a otro contenido normativo que se encuentra vigente en la legislación Colombiana; y quinto, el proyecto debe abstenerse de derogar el agravante de violencia de género contemplado para homicidio, por cuanto, éste es objeto de referencia directa en los agravantes del delito de lesiones personales y por ende su derogatoria implicaría que en ningún caso se podría agravar este último delito en caso de violencia de género con resultados distintos al deceso de la víctima.

176 Ministerio de Justicia, CSPC. Concepto enviado al Congreso de la Republica por el proyecto de Ley "Rosa Elvira Cely", 2014, núm. 4

177 Pues, al extender la figura de feminicidio a agresiones en contra de la mujer que no implican la violencia de género, el proyecto olvida que el fundamento para la mayor punibilidad de la conducta, no deviene del resultado material -que para el homicidio y feminicidio es el mismo-, sino del desvalor de la acción por contener una motivación misógina, razón por la que es necesario limitar la aplicación de esta figura.

178 Adiciona normas al Código Penal acerca de la máxima punibilidad en el ordenamiento jurídico colombiano. 
202 Mujeres, atrocidad y castigo: un estudio de caso sobre las razones del movimiento de mujeres para penalizar el feminicidio en Colombia - David Fernando Cruz Gutiérrez

Posteriormente, el 16 de septiembre de 2014, se aprobó la modificación del orden del día que aplazó el trámite del proyecto. Lo que permitido que los ponentes presentaran una nueva versión que acogiera las recomendaciones del CSPC y solventara las dificultades expuestas. En este punto, dos factores influyeron para agilizar el trámite legislativo. Por un lado, la representante a la cámara Angélica Lozano tomó la vocería del proyecto e impulsó hábilmente el procedimiento legislativo, mientras que, por el otro, con la sumatoria del partido Centro Democrático y el Partido Conservador se dio un consenso entre todas las fuerzas políticas del Congreso en torno a la importancia de sacar adelante esta legislación. La ponencia con el nuevo texto se publicaría el cinco de mayo de 2015, resultando aprobada por unanimidad en la Comisión primera de la Carama de Representantes.

La ponencia para el cuarto y último debate se publicaría el 22 de mayo de 2015. Para este momento ya figuraban como coautoras ocho congresistas, incluyendo a Nora García Burgos y Marta Cecilia Ramírez Orrego por el partido Conservador y María Fernanda Cabal por el partido Centro Democrático. El cuarto debate tuvo lugar el 2 de junio de 2015 en plenaria de la Cámara de Representantes con una votación arrasadora de 87 votos favorables y uno contra ${ }^{179}$. Posteriormente, se concilió el proyecto en la Cámara de Representantes ${ }^{180}$ y en el Senado ${ }^{181}$ para, finalmente, pasar a Sanción Presidencial. La norma fue sancionada en el 6 de julio de 2015 por el presidente Juan Manuel Santos, convirtiéndose en la Ley 1751 de 2015 más conocida como Ley Rosa Elvira Cely ${ }^{182}$. En esta ocasión el mandatario afirmó:

Esta ley consagra el feminicidio como un delito autónomo, para garantizar la investigación y sanción de los actos violentos contra las mujeres por motivos de género y discriminación. Esto implica un aumento importante de penas para quienes cometan este delito contra las mujeres ${ }^{183}$.

179 Curiosamente el voto en contra es del Congresista German Navas Talero, perteneciente al Partido Polo Democrático alternativo.

$180 \mathrm{Si}$ desea revisar el acta vea: http://www.imprenta.gov.co/gacetap/gaceta.mostrar documento? _ _tipo $=02 \& p_{\text {_ numero }}=72 \& p_{\text {_ }}$ consec $=42950$

$181 \mathrm{Si}$ desea revisar el acta vea: http://www.imprenta.gov.co/gacetap/gaceta.mostrar

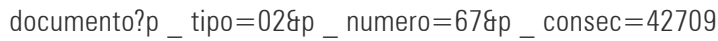

182 Nombrar a la Ley como Rosa Elvira Cely tuvo, como principal objetivo, que fuera por si mima una acción afirmativa que al llevar el nombre de una víctima que "encarnó múltiples violencias que se perpetran a las mujeres por el hecho de ser mujer, generara recordación sobre hechos que jamás debieron ocurrir y que jamás tendrían que volver a presentarse y por lo tanto que contribuyen a fortalecer un mensaje de repudio y de cero tolerancia a las violencias contra las mujeres. Así aforma Argot, 2017.

183 Semana. Distrito retiró polémico concepto en el caso de Rosa Elvira Cely. Bogotá D.C.: Revista Semana: http://www.semana.com/nacion/articulo/distrito-retiro-polemico-concepto-en-el-casode-rosa-elvira-cely/473846// 2016. 
La promulgación de la ley fue celebrada por la opinión pública, la Consejería Presidencial para la Equidad de la Mujer ${ }^{184}$ y por diversas lideresas del movimiento de mujeres.

Adicionalmente, paralelo al proceso legislativo, la familia de Rosa interpuso una acción de reparación directa en contra de la Fiscalía, la Policía Metropolitana y la Secretaria de Gobierno y de Salud de Bogotá, por cuanto -según argumentaban- se configuró una falla en el servicio, al menos por dos razones, primero porque sobre el victimario recaía una orden de arresto por delitos relacionados con agresiones sexuales y segundo, porque ante las llamadas de auxilio, los organismos de emergencia no actuaron con la rapidez y diligencia necesaria.

Ninguna de las entidades demandadas aceptó la responsabilidad que argüían los accionantes. Sin embargo, sería la Secretaría de Gobierno de Bogotá quién causaría de nuevo un revuelo, con su polémico concepto en el cual argumentaba que el hecho criminal tuvo lugar por culpa exclusiva de la víctima. De esta forma, la secretaria argumentaba que la muerte y violación de Rosa, era exclusivamente su culpa, por cuanto su participación -la de Rosa Elvira Cely- fue directa y eficiente en la producción del daño. Dice la repuesta de la Secretaria:

Todos sabían que (Javier Velasco y Mauricio Ariza, este último exculpado en el proceso) tenían comportamientos raros y los tildaban de malosos. No obstante, lo anterior, Rosa Elvira Cely salió a departir con ellos, se tomaron unos tragos (...) Puso en riesgo su integridad y vida, hasta el punto de que Javier Velasco le cercenó su existencia; si Rosa Elvira Cely no hubiera salido con los dos compañeros de estudio después de terminar sus clases en las horas de la noche, hoy no estaríamos lamentando su muerte..$^{185186}$

De esta forma la Secretaria de Gobierno, argumentó que Rosa Elvira Cely debió prever el riesgo que ni siquiera el centro de validación educativo en donde víctima y verdugo se conocieron, pudo prever. Esta respuesta no pasaría desapercibida, por el contrario, causaría un gran revuelo en la opinión pública, evidenciando, con especial fuerza, la necesidad de impulsar cambios en la sociedad orientados a la disminución

184 En aquel momento era la doctora Martha Ordoñez quién afirmo que esta ley es un instrumento clave "para combatir la violencia contra las mujeres" (El tiempo,2015).

185 Concepto de la Secretaria de Gobierno de Bogotá en el marco de un proceso de reparación directa promovido por los familiares de Rosa Elvyra Cey.

186 Este concepto a su vez, provocó que la abogada Luz Stella Boada de la secretaria que lo redactó, después que la misma secretaria afirmaría el concepto (El Colombiano, 2016), renunciara ante el revuelo que causo el concepto jurídico. También obligó a que el secretario de Gobierno de aquel momento, Miquel Ángel Uribe Turbay pidiera disculpas públicamente. 
204 Mujeres, atrocidad y castigo: un estudio de caso sobre las razones del movimiento de mujeres para penalizar el feminicidio en Colombia - David Fernando Cruz Gutiérrez

de la violencia de género, empleando, entre otros mecanismos, y con fuerte respaldo institucional al derecho penal.

Sin embargo, como efecto colateral, el escandalo volcó a la opinión pública a resaltar la importancia del delito de feminicidio en Colombia lo que, a su vez, opacó las pocas voces disidentes que advertían sobre los distintos problemas que implica fortalecer el derecho penal en un Estado como el colombiano, en dónde existe una adicción punitiva ${ }^{187}$ por la cual se incrementan progresivamente las penas y los delitos ${ }^{188}$ y, al mismo tiempo, dichas penas, tal como lo resalta la Corte Constitucional189 en su jurisprudencia ${ }^{190}$, se cumplen en condiciones inhumanas, haciendo que el sistema penitenciario se convirtiera en un escenario de violación sistemática de derechos ${ }^{191}$.

\section{Una respuesta compleja}

Para responder al interrogante planteado en la introducción del texto (recapitulando:ipor qué los movimientos de mujeres demandan la punición de conductas en Colombia? ?) se articuló la respuesta, por su complejidad, en tres niveles distintos: en el primer nivel, siendo el más superficial, se exponen las razones pragmáticas que soportaron la pretensión del movimiento de mujeres de integrar al estatuto penal el feminicidio como delito autónomo; en el segundo nivel, de profundidad media, se propone una relectura de crimen atroz y la máscara de monstruosidad como una oportunidad política para apalancar una reforma al estatuto penal de corte punitiva; y finalmente, una conclusión, a partir de las expresas motivaciones que gran parte del movimiento de mujeres, se evidencia el particular sincretismo ideológico entre los postulados del movimiento y el funcionalismo radical, frente al papel del derecho penal y el castigo en la sociedad.

187 El término adicción punitiva tiene un impacto simbólico en el trabajo citado, por cuanto hace referencia a las desproporciones punitivas de las penas relacionadas con la lucha contra las drogas.

188 Uprimny, Esther y Parra. Penas alucinantes. La desproporción de la penalización de las drogas en Colombia. Bogotá: Dejusticia. 2013.

189 Cabe aclarar que la ley Rosa Elvyra Cely fue demandada ante la Corte Constitucional por Juan Sebastián Bautista Pulido. La consecuente sentencia - C 297 de 2016-, declaró la exequibilidad de la disposición jurídica, afirmando que es constitucional teniendo en cuentan el marco de protección legal de la mujer, tanto, en virtud del bloque de constitucionalidad, como de las disposiciones internas.

190 La Corte Constitucional declaró la figura de "estado de cosas inconstitucional" a la situación penitenciaria por primera vez en la sentencia T 153 de 1998.

191 Ariza, Libardo y lturralde, Manuel. Los Muros de la Infamia. Prisiones en Colombia y América Latina. Bogotá D.C.: Ediciones Uniandes. 2011. Estos autores muestran que las condiciones materiales de las prisiones colombianas violan los estándares mínimos de salubridad y dignidad, por distintos problemas, entre ellos el hacinamiento. 


\subsection{Las razones pragmáticas}

La Ley Rosa Elvyra Cely está soportada por unas razones pragmáticas que son importantes reconocer. En la ley 1257 de 2008 se dejó de lado la posibilidad de incluir el feminicidio dentro del Estatuto penal ${ }^{192}$ y se optó por incluir un agravante genérico en el artículo del tipo penal de Homicidio -artículo 104 del Código Penal-, en caso que el resultado tipifico estuviera motivado por el hecho de ser mujer. La aplicación del agravante, a los ojos de algunas activistas del movimiento de mujeres, resultó inadecuada ya que la mayoría de los Fiscales, o lo aplicaban para todo o para nada, dejando de lado el propósito de dicho agravante que era demostrar el desvalor especial que implica la violencia contra la mujer, cuando esta se encuentra inmersa una posición de subordinación y discriminación frente al hombre. Incluso, en una de las entrevistas realizadas en el marco de esta investigación se comentó, al respecto de los abogados de elite, que, a pesar de su posición e importancia en mercado de jurídico, no conocían ni manejaban de forma adecuada el agravante y preferían no integrarlo al procedimiento penal aun cuando era relativamente fácil hacerlo, especialmente en casos donde era evidente la violencia de contenido sexual.

En consecuencia, una parte importante de las activistas consideraba necesario contar con elementos objetivos que clarificaran los casos en los que era aplicable el agravante. Esta razón tenía asidero jurídico hasta el 4 de marzo de 2015, fecha en la cual la Sala Penal de la Corte Suprema de Justicia se pronunció, señalando los casos en los que era aplicable el agravante y definiendo el contenido del siguiente literal: "por el hecho ser mujer" de esta forma ${ }^{193}$.

se causa la muerte a una mujer por el hecho de ser mujer, cuando el acto violento que la produce está determinado por la subordinación y discriminación de que es víctima, de lo cual resulta una situación de extrema vulnerabilidad. Este entorno de la violencia feminicida, que es expresión de una larga tradición de predominio del hombre sobre la mujer, es el que básicamente ha servido de apoyo al legislador para considerar más grave ese tipo de violencia que se genera en un contexto de desigualdad y que se busca contrarrestar legítimamente con la medida de carácter penal examinada e igual con las demás de otra naturaleza adoptadas en la Ley 1257 de $2008 .^{194}$

192 L. Siıva, entrevista personal, 7 de febrero de 2018; Esta decisión fue adoptada por la Bancada de Mujeres dentro del Congreso de la República, dejando por fuera la voz de una parte importante del movimiento de mujeres.

193 SÁnchez, A. M. \& León F., 2015

194 CSJ, 2015, M.P. Patricia Salazar Cuellar. 
206 Mujeres, atrocidad y castigo: un estudio de caso sobre las razones del movimiento de mujeres para penalizar el feminicidio en Colombia - David Fernando Cruz Gutiérrez

Sin embargo, para la fecha de publicación de esta sentencia el proyecto legislativo ya estaba en curso, y durante su transcurso se consolidaron los elementos objetivos del tipo, recogiendo del agravante la expresión "por la condición de ser mujer", adicionando "por motivos de identidad de género" -ampliando el rango de aplicación de la norma a la comunidad LGTBI- y más importante aun especificando seis casos en los cuales es de obligatoria tipificación el delito de feminicidio, diferenciándolo de forma tajante del tipo penal de homicidio así: i) cuando exista una relación de intimidad entre víctima o victimario -sin importar si es romántica o no-, ii) que se encuentren presencia de actos de instrumentalización sobre el cuerpo de la víctima, iii) aprovechamiento de relaciones de poder sobre la víctima para el resultado típico -por ejemplo, de índole económico-, iv) cometer el delito para generar terror o humillación a quien se considere enemigo ${ }^{195}$, v) la existencia de antecedentes de violencia 0 amenaza del sujeto activo de la conducta frente a la víctima y vi) que durante el tiempo previo a la muerte la víctima haya sido privada de su libertad de locomoción ${ }^{196}$.

\subsection{De la atrocidad a la oportunidad política}

Las sociedades contemperarías han creado un grupo de reglas para regular la aplicación del poder punitivo del Estado. Este grupo de reglas, conocido como derecho penal, selecciona a un grupo reducido de personas para aplicar una pena. Zaffaroni, Aliaga \& Slokar ${ }^{197}$ argumentan que esta selección sucede en dos momentos distintos: la criminalización primaria y la segundaría ${ }^{198}$. La primaría usualmente es llevada a cabo por el poder legislativo -en excepción por el poder ejecutivo-y corresponde a la sanción de una ley penal que permite 0 habilita la punición de un conducta particular; mientras que la segundaria, corresponde a la acción punitiva ejercida sobre personas concretas y sucede

195 Esta condición de aplicación fue una lucha importante del movimiento de mujeres en Colombia, especialmente por la cantidad de agresiones sexuales que se dieron en el marco del conflicto armado y que, según el CNMH (2014), obedecieron en muchos casos a estrategias militares entre los distintos actores del conflicto.

196 Cuervo, V., Vega, L., Márouez, A. y Román V. Feminicidio, impunidad o seguridad jurídica en la política criminal colombiana. Revista Verba luris, 12(37), pp. 109-118. 2017.; Cabe indicar que según IsABEL Agatón (2017) el tipo penal autónomo del feminicidio tiene incidencias importantes en avance de la protección a las mujeres. Especialmente frente al uso que los fiscales posteriormente le han dado a este delito (p. 160 ss.).

197 Zaffaroni, Eugenio Raúl, Alagia, Alejandro \& Slokar, Alejandro. Derecho Penal, Parte General. Editorial Ediar, segunda edición. Buenos Aires: ediar. 2002.

198 Otros autores, especialmente Ferrajoli, consideran que la criminalización se realiza en tres momentos. A diferencia de ZaFARroNI (2002), Ferrajoli considera que la criminalización segundaría responde al momento de investigación y judicialización, y la criminalización terciaria corresponde a aplicación de la pena. 
cuando las agencias policiales detectan a una persona que ha cometido una conducta previamente criminalizada, la ponen a disposición judicial y si el juez, en discusión pública y obediencia de las reglas de selección, confirma que la persona cometió la conducta, aplica la consecuencia jurídica, es decir la pena. En este proceso de criminalización, tanto primaria como segundaria, existen un flujo importante de emociones públicas ${ }^{199}$.

De acuerdo a Nussbaum ${ }^{200}$, estas emociones también implican evaluaciones sobre determinadas realidades que no se reducen a meros impulsos, sino que por el contrario tienen un contenido importante que se emparenta con proyectos políticos comunes. En otras palabras, las emociones públicas tienen un fuerte contenido evaluativo del contexto social en que se despliegan e influyen en él. En la criminalización primaria, el papel de las emociones, especialmente el miedo y la rabia frente al delito resultan especialmente relevantes ${ }^{201}$. De acuerdo a Boers ${ }^{202}$ y Frevel ${ }^{203}$, el miedo al crimen se puede expresar como un sentimiento social que trasciende la experiencia individual a convertirse en víctima de un ilícito, para desplegarse en una dimensión colectiva frente a conductas que se entienden como amenazas al conjunto social.

El espectro público de estas emociones sociales está ampliamente ligado con lo que Garlan llama puntitivity o punitividad, es decir con el fenómeno de reaccionar ante el crimen a través del castigo. La relación, como argumenta Ambrost ${ }^{204}$, es que en las sociedades con un flujo elevado de emociones públicas de miedo y rabia hacía el crimen, son más propensas a tramitar paquetes de reforma pena|205 que empiezan

199 Freiberg, 2001.

200 Nussbaum, Martha. Political emotions: Why Love Matters for Justice. Cambrige, Massachusetts. Harvard University Press. 2013.

201 Windzio, M., Simonson, J., Pfeiffer, C., Kleimann, M. Kriminalitätswahrnehmung und Punitivität in der Bevölkerung - Welche Rolle spielen die Massenmedien? Forschungsbericht. Hannover: KFN. 2007, 59; Langworthy and Whitehead, 1986; Costelloe, M.T. "The social correlates of punitiveness toward criminals: A comparison of the Czech Republic and Florida". Justice System Journal, 23, 191-220. 2002; Dowler, K. 2003; Karstedt, S. "Emotions and criminal justice". Theoretical Criminology, 6, 299317. 2002. P. 302; Ambrost, Adres. "How Fear of crime affects punitive attitudes". European Journal of Criminal Policy and Research (23) pp. 461-481. 2017.

202 Boers, K. "Kriminalitätsfurcht - Über den Entstehungszusammenhang und die Folgen eines sozialen Problems", en Hamburger Studien zur Kriminologie; 12 Pfaffenweiler: Centaurus. 1991. p.207.

203 Frevel, B. Polizei, "Politik und Medien und der Umgang mit dem bürgerschaftlichen Sicherheitsgefühl". In H. J. Lange (Ed.), Die Polizei der Gesellschaft(pp. 321-336). Wiesbaden: VS Verlag für Sozialwissenschaften. 2003. P. 325.

204 Ambrost, 2017.

205 También señalan que, si bien el enojo es un factor importante, también existen otros factores como prejuicio racional, el miedo al crimen ciertas atribuciones para comportamiento criminal y la ideología política --especialmente conservadurismo político-- (JoHnson, 2009). 
208 Mujeres, atrocidad y castigo: un estudio de caso sobre las razones del movimiento de mujeres para penalizar el feminicidio en Colombia - David Fernando Cruz Gutiérrez

a desdibujar la racionalidad del ius puniendi a cargo del Estado. Adicionalmente, este tipo de emociones generan disensos sociales en los mecanismos que se consideran adecuados para tratar el fenómeno criminal ${ }^{206}$, abriendo la puerta a que se pasen por alto la voz de los expertos en el tema y se favorezca las demandas del público, que en la mayoría de los casos abogan por medidas que privilegian tanto la eficiencia del procedimiento penal -antes que el respeto de garantías y derechos fundamentales-, como el aumento en la duración y fortaleza de las penas.

En este orden de ideas, estas emociones públicas - miedo y rabia especialmente ${ }^{207}$ tienen un contenido evaluativo, que se despliega sobre el disenso social frente al tratamiento del fenómeno criminal. Usualmente, este tipo de sentimientos se ven acrecentados en caso de manifestaciones criminales que tienen rasgos monstruosos, es decir, aquellas conductas que no pueden encasillar bajo el paraguas del sujeto racional que actúa de acuerdo a fines. La reacción social ante este tipo de actos es de ruptura, pues el sujeto promedio es incapaz de reconocerse en el criminal salvaje -o monstruoso- por los niveles desbordados de violencia que implican sus actos. Sin embargo, deslindarse del criminal implica tanto un ejercicio de identificación y evaluación, como de señalamiento y asignación. La sociedad se identifica por fuera del criminal, lo entiende como una anomalía que no hace parte de sus mecanismos de producción de sentido, y por lo tanto lo desconoce y le asigna un lugar como un otroincluso como un extremo otro-.

Sin embargo, este acto de deslindamiento, como lo afirma Tonkonoff "vuelve a señalar lo ilusorio de todo cierre social"208 . Cada acto de atrocidad desmedida, señala la inoperancia de los límites que la misma sociedad marcó y al mismo tiempo la necesidad que dichos límites sean más certeros. En este sentido, el acontecimiento de un crimen monstruoso y las emociones que despierta, se muestran como un espacio de rompimiento, en donde el sujeto social se siente tanto inseguro como consternado y busca mecanismos para solventar estos sentimientos. En esta búsqueda aparece el castigo, como un ejercicio de reafirmación de la moral social y del sistema de expectativas normativas, que propone una forma de estabilización del flujo de sentido que el acto criminal rompió.

206 Pratt, J. Penal Populism. London: Routledge. 2007.

207 No son las únicas emociones. Por ejemplo, ItURRALDE (2012) y HASSERMER (1995) consideran que las ansias que genera la criminalidad también son un factor explicativo de políticas criminales de mano dura.

208 Tonkonoff, Sergio. "Acerca del crimen, el criminal y las reacciones suscita". Delito y sociedad: Revista de ciencias sociales (23) pp. 89-104. 2007. p. 91 
Este mismo espacio de búsqueda se puede leer desde otro punto de vista teórico como una oportunidad política ${ }^{209}$. De acuerdo a Tarrow ${ }^{210}$ las oportunidades políticas se despliegan en entornos determinados ofreciendo incentivos para formas de acción colectiva. Melucci211, complementando a Tarrow, argumenta que estos incentivos operan como un marco de posibilidades y límites para la acción colectiva que están anudados a realidades concretas que si bien dependen del contexto, también sirven para modificarlo a través de su uso estratégico por parte de los movimientos. En este sentido los crímenes atroces, especialmente en casos en los que la víctima tiene una condición étnica, de orientación sexual, o de género que resulta determinante para la comisión del injusto y su posterior representación, sirven como fuerte incentivo a la acción colectiva ${ }^{212}$.

En concreto, como reseña Isabel Agatón, el asesinato de Rosa Elvira Cely y su respectivo cubrimiento por parte de los medios de comunicación, posicionó en el foro público tres temas importantes: i) desplegó en la palestra pública la práctica del empalamiento como una modalidad de violencia sexual y tortura ${ }^{213}$, ii) ubicó en el escenario público la magnitud de la violencia sexual en la sociedad colombiana y finalmente iii) unió y congregó a la opinión pública en el reclamo de justicia y reparación para las víctimas ${ }^{214}$. En este contexto, se dieron diversas formas de acción colectivas incentivadas por la atrocidad del hecho criminal, que van desde intervenciones de personalidades notables del movimiento de mujeres en los medios más importantes de comunicación, hasta la construcción de informes técnicos para la recopilación de información sobre casos feminicidio.

Sin embargo, en el campo jurídico, la acción colectiva más notable es la construcción de un proyecto legislativo por parte del Centro de Investigación en Justicia y Estudios Críticos del Derecho [en adelante Cijusticia], integrada por personajes notables dentro

209 Como referente teóricos principales se tienen a TARrow (1997), a EIsInger (1973) y a Melossi (1994).

210 Tarrow, Sidney. El poder en movimiento. Los movimientos sociales, la acción colectiva y la política, Madrid, Alianza Universidad. 2017.

211 Meluccl, Alberto. "A strange kind of Newness: what's "new" in New Social Movement". en E. Laraña et al., New Social Movement, Philadelphia, pp. 55-72. 1994

212 El caso de Rosa Elvira Cely no es el único que ha auspiciado formas de acción colectivas importantes. Otro tipo de hechos criminales alrededor del globo han incentivado formas de acción colectivas importantes, entre ellas: el incendio del viaje de la libertad (MARSHAL, 2005).

213 Una parte importante del movimiento de mujeres dedico amplios esfuerzos a visibilizar que el empalamiento es una práctica de subordinación y tortura utilizada con frecuencia en el marco del conflicto armado.

214 Agaton, 2017. P. 157-158. 
210 Mujeres, atrocidad y castigo: un estudio de caso sobre las razones del movimiento de mujeres para penalizar el feminicidio en Colombia - David Fernando Cruz Gutiérrez

del movimiento como Isabel Agatón ${ }^{215}$ y Nidia Olaya Prada ${ }^{216}$ que, posteriormente, sería presentado al Congreso por la senadora Gloria Inés Ramírez, convirtiéndose, con los cambios especificados en el numeral 4 de este texto, en la Ley Rosa Elvyra Cely. En gran medida, el surgimiento de esta oportunidad política y su respectiva articulación con el Congreso de la República, está ligada a los rasgos atroces del crimen y a su capacidad para representar y encausar un flujo importante de emociones públicas que demandan la criminalización.

De esta forma, la atrocidad se convierte en una oportunidad política. "La violación, el empalamiento y posterior asesinato de Rosa Elvira Cely (...) hizo patente la necesidad de nombrar una realidad"217; el contexto, en consecuencia, facilito que la sociedad y el estamento político, "con todo el dolor del caso"218, apoyará la tipificación del delito autónomo de feminicidio. La criminalización, en consecuencia, funcionó como el mecanismo por el cuál la sociedad se diferenció de monstruo, saliendo del vértigo, la ansiedad y el miedo que produce la perdida de sentido que origina un acto de tal atrocidad.

A su vez, el lenguaje del trauma, esto es, la movilización del cuerpo alterado empalado en este caso-, enfermo o violentado, anudado al sufrimiento psicológico como estrategia de comunicación verbal, tiene un alto impacto, para la acumulación de capital político. Cómo explica Fassin ${ }^{219}$, el lenguaje del trauma tiene como consecuencia un flujo de emociones compasivas, especialmente desde la sociedad al doliente, que van acompañadas de la movilización de capitales, tanto simbólicos como materiales, para aliviar la situación de la víctima. Este lazo de compasión permite que la sociedad se reconozca a sí misma, identificándose como comunidad moral que atiende el llamado de la víctima, soportando con recursos y viabilidad política algunas de sus demandas.

Este doble haz, que de un lado pone al miedo y la rabia frente al crimen, y al otro a la compasión frente al vulnerado o doliente, conforma una economía moral220

215 Directora del centro de investigación Cijusticia, profesora e investigadora en la Universidad Nacional de Colombia y de la Universidad Autónoma de Colombia. Autora de Justicia de Género: un asunto necesario (2013) y Si Adelita se fuera con otro: del feminicio y otros asuntos (2017).

216 Actualmente se desempeña como Abogada de la Secretaría de la mujer.

217 Agaton, 2017, p. 156.

218 L. Silva, entrevista personal, 7 de febrero de 2018

219 Fassin, D. y Rechtman, R.. The Empire of Trauma. An inquirí into the condition of victimhood. Pinceton University Press, 6 Oxford Street, United Kingdom. 2009.

220 Este término --economía moral-- fue acuñado por E.P Thomson (1971), quien la entendía como a un conjunto de prácticas, normas, obligaciones y expectativas de una clase social específica, en su estudio del proletariado y el campesinado, que constituían una forma de relacionarse y de posicionarse en contra de una economía de mercado implícitamente inmoral. Posteriormente, 
frente a lo atroz ${ }^{221}$, es decir, una forma de producción, circulación y apropiación de normas, obligaciones, valores y afectos, en la cual, la condición de víctima es expuesta a través del lenguaje del trauma, y del victimario a través de la imagen del monstruo, privilegiando el doble imperativo de compasión y castigo, como formas de identificación y exclusión social, respectivamente.

\subsection{Una proximidad inesperada: el feminicidio como funcionalismo radical}

El debate sobre el uso del derecho penal está íntimamente ligado a la funcionalidad que se le otorga la pena. Parafraseando a Enrique Bacigalupo ${ }^{222}$, las funciones de la pena, como conjunto de ideas que sirven de sustento para legitimar una limitación a la libertad a través del ius puniendi del Estado, son muestra de una ideología sobre el castigo que antes que enmascarar la realidad, sirve para revelarla. Este conjunto de ideas presupone determinada concepción del crimen y la criminalidad, fundamental para determinar la reacción que debe tomar el Estado con el objetivo de afrontarla. En este sentido la función de la pena es responder a la nada fácil pregunta: ¿qué puede hacer el Estado legítimamente con el autor de un delito?223.

Este interrogante, transversal tanto al derecho penal como al derecho constitucional, tiene una relación estrecha con el cuestionamiento que inspira este trabajo. La pregunta sobre qué puede hacer legítimamente el Estado con un delincuente, está ligada de cerca a los motivos que tiene el movimiento de mujeres para demandar la criminalización de una conducta. El punto de unión entre ambos es el

el termino lo desarrolló James Scott (1990) trasladándolo al campo de las ciencias sociales especialmente la antropología.

221 La importancia de esta nueva economía moral que describe FASSIN (2009) es su capacidad para explicar porque ciertos grupos con condiciones particulares utilizan su propia condición de víctimas y la exponen con el fin de adquirir capitales materiales y simbólicos. Fenómeno que se manifiesta con bastante fuerza en el ámbito de las políticas públicas, permitiendo a los estados encausar miedos y ansiedades sociales que surgen de la relación entre aquel que expone su trauma y quien lo observa, legitimando a los ojos del espectador --movido por la compasión--, la actuación del poder público. Lo que también podría aplicarse al campo de las políticas criminales, pues como lo explica ITURRALDE (2007) lo estados debilitados por las fuerzas del mercado, en sociedades acosadas por la pobreza, el desempleo y la inseguridad, responden a través de políticas represivas a diversos sentimientos por parte de la ciudadanía, entre ellos miedos, ansiedad y compasión, con el objetivo de mostrase fuertes y aumentar su legitimidad (pág. 111).

222 Bacigalupo, Enrique. "Filosofía e Ideología de las Teorías de la Pena". Derecho y Humanidades (16), pp. 17-30. 2010.

223 Ibídem. 
212 Mujeres, atrocidad y castigo: un estudio de caso sobre las razones del movimiento de mujeres para penalizar el feminicidio en Colombia - David Fernando Cruz Gutiérrez

fundamento de la pena, pues este conjunto de ideas cristaliza una visión sobre el papel del derecho penal en la sociedad. En consecuencia, el primer paso para responder estos interrogantes es delimitar el concepto de pena.

En el campo de la sociología del castigo varios autores, desde Foucault a Melossi, han realizado aportes importantes para entender su significado. Sin embargo, es Durkheim quién sienta las bases de este campo de estudio argumentando que el castigo, como hecho social, responde a la necesidad de estructurar las bases de un sistema moral operativo. "Para Durkheim, los hechos sociales constituyen modos de acción y representación ampliamente extendidos dentro de una sociedad concreta, en tanto que son compartidos por cada uno de sus miembros"224.

De esta forma, la pena se plantea como un hecho social objetivo, marcando distancia de la venganza, que se entiende como subjetiva, derivada de una manifestación de voluntad por parte del individuo. La venganza, en consecuencia, era válida en un estado natural pre social, mientras que la pena se entiende como legitima en el marco de la organización de una sociedad y por ende está sometida a un criterio racional que no depende del individuo, de su psiquis o biología, sino que hace parte de la construcción de lo social, de donde adquiere su pretensión de objetividad. Si bien Durkheim es criticado por considerar al individuo como un mero receptáculo de los hechos sociales y no como un participe en su construcción, su aporte en este campo es delinear la función expresiva del hecho social. En el caso de la pena, esta función expresiva $^{225}$ implica que la acción de castigar se torne como imposición a los modos de sentir, pensar y obrar de los individuos dentro de la sociedad.

Una parte importante de los fundamentos de la pena se enmarcan en esta capacidad expresiva que señala Durkheim. Becaría, por ejemplo, siendo uno de los padres del derecho penal moderno, llegaría a afirmar que la función de la pena no es más que "impedir al reo a no hacer nuevos daños a sus conciudadanos y motivar a los demás a no hacerlos de la misma manera"226. Doctrinalmente, la última parte de la

224 Vásouez Gutiérrez, Juan Pablo. "La concepción de hecho social en Durkheim. De la realidad material al mundo de las representaciones colectivas". Política y Sociedad Vol. 49 (Núm 2.), pp. 331-351. 2012. P. 333.

225 Más recientemente, autores como Hassermer (1995), Cófre (2001), y Díez (2003) han hecho hincapié en esta función expresiva, señalando que toda norma penal tiene un contenido expresivo, en el que realizan determinada comunicación. Donde disienten es en el contenido de esta comunicación, mientras que HASSERMER (1995) y RíEz (2003) consideran que una norma penal tiene un contenido expresivo polisémico, es decir que envía diferentes mensajes, Cofre (2001) considera que el castigo tiene un mensaje eminentemente moral, e incluso destaca que la forma en cómo se castiga está directamente relacionada con la buena conciencia de la sociedad.

226 Becaría, Cesare. Tratado de los Delitos y las Penas. Madrid: Universidad Carlos III de Madrid. 2015. P. 34. 
afirmación de Becaria se conoce como la función preventiva-general de la pena y su versión clásica o negativa, a pesar que nace con Becaría, es ampliamente desarrollada por autores de la talla de Bentham, Feuerbach y Romagnosi, cuyo principal fundamento puede resumirse en que la razón justificativa de la pena es intimidar a los individuos para desincentivar la comisión de ilícitos.

Intuitivamente, la Ley 1741 de 2015 que integra el feminicidio al estatuto penal, parece encajar con esta función preventivo general de la pena en su versión negativa. Esto, por cuanto el principal argumento que se encuentran en la exposición de motivos de dicha ley es que las mujeres tienen un mayor riesgo de perder su vida por causas relacionadas a la violencia en espacios íntimos o familiares que por otras causas, como accidentalidad o violencia económica [especialmente en caso de robos y atracos] ${ }^{227}$, haciendo necesario que el ordenamiento legal reaccione frente a estas conductas. El argumento adquiere mayor fuerza por la forma como está organizada la información, pues al igual que el caso de Holanda y de Italia, los datos cuantitativos tienen una especial importancia y cubren la mayor parte de la exposición de motivos. Sin embargo, este mismo argumento sirvió de base para la ley 1257 de 2008, por medio de la cual se adoptaron normas para la sensibilización, prevención y sanción de formas de violencia contra la mujer, y por lo tanto no explica la necesidad de integrar el delito de feminicidio de forma autónoma al estatuto penal, a pesar que esta reforma siga la tendencia, hace tiempo criticada, del uso político de la función preventiva general de la pena en su modalidad negativa, que trae como consecuencia el aumento paulatino de su duración e intensidad hasta superar su uso racional/proporcional, con el objetivo, cada vez menor, de desincentivar a los infractores y cada vez mayor de legitimar a los actores políticos que explotan los réditos de dichas reformas.

Además de la versión negativa, la función preventivo general tiene otra cara influida directamente por los alemanes Claus Roxin ${ }^{228}$ y -más recientemente- Günter Jakobs, quienes la han orientado hacia el pensamiento funcionalista. Para Roxin la intervención del derecho penal únicamente se justifica por su eficacia para solucionar problemas sociales. Por ende, todas las categorías dogmáticas del derecho penal deben estar orientadas hacia este objetivo, incluyendo la teoría de la pena. Desde

227 Si desea profundizar vea: Exposición de Motivo, Ley Rosa Elvira Cely, Pág. 7.

228 Roxin, Claus. Offene Tatbestände und Rechtspflichtmerkmale, 2.a ed., Berlín: Walter de Gruyter. 1970; Roxin, Claus. "El desarrollo del Derecho Penal en el siguiente siglo", en Dogmática Penal y Política Criminal, Lima: Idemsa.1998; Roxin, Claus. "Las formas de intervención en el delito: estado de la cuestión", en Sobre el estado de la teoría del delito (Seminario de la Universitat Pompeu Fabra), 1.a ed., Madrid: Cuadernos Civitas. 2000; Roxin, CLaus. Política criminal y sistema del derecho penal, 2.a ed., Buenos Aires: Hammurabi. 2002. 
214 Mujeres, atrocidad y castigo: un estudio de caso sobre las razones del movimiento de mujeres para penalizar el feminicidio en Colombia - David Fernando Cruz Gutiérrez

esta acera, Roxin formula la teoría preventivo integradora que conjuga elementos de la prevención general como de la prevención especial -desarrolladas anteriormente-. La textura mixta de la teoría de Roxin (1998) es tajante al abandonar el retribucionismo penal, y sostiene que a través de la prevención, tanto general como especial, se pueden consolidar los espacios necesarios para que el derecho penal solucione los problemas sociales que justifican su existencia.

Bajo el esquema propuesto por Roxin la pena es tanto inoculadora y resocializadora del criminal como defensora y afirmadora de los bienes jurídicos protegidos. Esta integración, tiene un importante atractivo teórico porque permite una baraja de posibilidades de acción. Sin embargo, en el caso de la prevención especial, es decir del fundamentado de la pena en su respectiva aplicación para el criminal, Roxin defiende que el sustento del reproche penal es la culpabilidad del delincuente, postura que se aleja de argumento que considera que la pena sirve, ante todo, para inhabilitar al criminal, pues él considera que el camino para enfrentar la peligrosidad del delincuente no es aumentar la intensidad o duración de la pena, sino utilizarla para poner en marcha procedimientos de reeducación y resocialización. En este punto, la Ley Rosa Elvira Cely, al impedir el acceso a subrogados penales y sustitución de la pena, parece primar por una versión de la prevención especial negativa que neutraliza al criminal al sustraerlo de la sociedad. De hecho, en el proceso de inclusión de la conducta al estatuto penal para habilitar su punición, lo que Zafarroni llama criminalización primaria, se consolida jurídicamente un nuevo tipo de criminal con un fuerte desvalor simbólico para la sociedad: el feminicida, que sigue la peligrosa tendencia de concebir a los criminales como individuos sobre los que no es posible consolidar expectativas cognitivas por parte de la sociedad.

Este cambio en la configuración política del tratamiento de este tipo de criminal, parece ir más en la vía del funcionalismo radical elaborado Günter Jakobs ${ }^{229}$ que bajo el esquema propuesto por Roxin. Jakobs proviene de una tradición de pensamiento altamente influida por los planteamientos de Kant y Hegel ${ }^{230}$ que considera que la función

229 JakoBs, Günther. "Sociedad, norma, persona; en una teoría de un Derecho penal funcional", traducida por Cancio Meliá y Bernardo Feijoó, en Cuadernos de conferencias y artículos No 13, Centro de Investigaciones de Derecho Penal y Filosofía del Derecho. 1996; Jakobs, Günther. "iCómo protege el Derecho penal y qué es lo que protege? Contradicción y prevención; protección de bienes jurídicos y protección de la vigencia de la norma", en los Desafíos del Derecho penal en el Siglo XXI, Libro homenaje al Profesor Dr. Günther Jakobs. Lima: Ara Editores. 2005; JakoBs, Günther. "La imputación jurídico-penal y las condiciones de vigencia de la norma", en Teoría de Sistemas y Derecho Penal, Fundamentos y Posibilidad de Aplicación, Traducción a cargo de Javier Sánchez-Vera Gómez-Trelles y Carlos Gómez-Jara Díez.Lima: Ara Editores. 2007.

230 Una parte importante de los filosos ilustrados desconfiaban sobre la propuesta de fundamentar la pena más allá de sí misma. KANT (2003), que está en la cima de este pensamiento ilustrado, 
preventiva de la pena, con énfasis en su versión especial ${ }^{231}$, afecta decididamente la dignidad de la persona, pues implica su tratamiento como cosas. Esta decidía frente a la prevención especial lleva a Jakobs a advertir que la verdadera función del derecho penal y con esto de la pena, es ratificar la norma vulnerada por el criminal, más no el tratamiento del delincuente, que considera se debe endilgar al derecho de policía. Para Jakobs las normas jurídicas implican expectativas de comportamiento en una circunstancia y situación determinada sobre cada uno de las personas que integran la sociedad, e incluso, son constitutivas de su identidad, en términos de deberes, derechos y libertades ${ }^{232}$. De esta forma, para Jakobs sin normas no hay sociedad y al derecho penal, de forma consecuente, se le confía el mantenimiento de esta identidad.

Esta labor, que para Jakobs es fundamental, resulta en una importante valoración de la actividad de castigar, emparentada de cerca al ideal de la defensa de la sociedad, antes que a las reiteradas críticas al sistema punitivo esgrimidas tanto por su incapacidad para resolver los problemas sociales en los que interviene ${ }^{233}$, como por servir a intereses de carácter hegemónico ${ }^{234}$. En este sentido, la pena funciona como un acto de vigencia del sistema jurídico que confirma la identidad normativa de la sociedad, resultando así bastante atractiva para demostrar un ideal de conducta.

consideraba que cualquier justificación a la pena implicaba mediatizar al ser humano, lo que resultaba inaceptable para su propuesta filosófica por cuanto afecta el imperativo moral que es transversal a su obra: que el hombre es un fin en sí mismo, e incluso, aun cuando moralmente merece un castigo, Kant rechaza, en cualquier situación, que se le pueda mediatizar por este medio. Hegel, en una dirección muy parecida, considera que la pena al negar el delito, es la afirmación del derecho, e incluso honra al delincuente al tratarlo como un ser racional con la capacidad de entender las consecuencias morales de sus actos.

231 La teoría de la prevención de la pena en su versión especial trata los efectos que tiene la aplicación de una pena en el individuo a la que va dirigida. El principal objetivo de esta clase de prevención es evitar que la persona que haya cometido un ilícito, vuelva a cometer alguno en el futuro. Así, la prevención especial no va dirigida al conjunto de la sociedad, sino a aquellos que ya hayan vulnerado el ordenamiento jurídico.

232 Esta idea está muy influida por la visión de Niklas Luhmann sobre las personas como subsistemas de un sistema mayor, que es la sociedad. Al ser subsistemas, las personas dependen de un sistema mayor, del cual adquieren sus deberes y derechos, pero al mismo tiempo esto mismo sistema puede limitar esto.

233 Hulsman, 2003; Gómez, 2008

234 Barattam 1982; Loïc Wacouant. Castigar a los pobres: el gobierno neoliberal de la inseguridad social. Barcelona: Gedisa. 2010; Geor Rushe y Otto Kirchelmer. Punishment and Social Structure. New York: Columbia University Press. 2009.

En este punto, se incluyen dentro de interés hegemónico intereses de distinto orden tanto económico, social, racial o heteronormativo que busquen el mantenimiento de la estructura social. 
216 Mujeres, atrocidad y castigo: un estudio de caso sobre las razones del movimiento de mujeres para penalizar el feminicidio en Colombia - David Fernando Cruz Gutiérrez

La relación entre castigar y demostrar está en la apuesta del movimiento de mujeres y su relación con el derecho penal. En palabras de Isabel Agatón:

la necesidad de trascender el aspecto puramente normativo y hacer que la iniciativa para la creación del tipo penal autónomo fuera por su misma una acción afirmativa que, al llevar el nombre de Rosa Elvira Cely, como una víctima que encarnó múltiples violencias que se perpetran a las mujeres por el hecho de ser, generara recordación sobre hechos que jamás debieron ocurrir y que jamás tendrían que volver a presentarse y por lo tanto que contribuyera a florecer el mensaje de repudio y de cero tolerancia a las violencias contra las mujeres. ${ }^{235}$

En consecuencia, participar en la definición de lo criminal, implica participar en la construcción de los bienes jurídicos que se quieren proteger y -siguiendo la propuesta de Jakobs - en la identidad normativa de la sociedad y de las personas que la integran.

La pena, en este sentido, se convierte en un acto de comunicación sobre una defraudación de expectativas - o comunicación defectuosa- que sigue el planteamiento dialectico de Hegel236 $^{23}$ en cual, al negar el delito, afirma automáticamente la norma. Este móvil de negar una realidad como la colombiana, con cifras preocupantes de violencia de género, para afirmar normativamente la importancia del bien jurídico de la vida de la mujer, resulta de especial importancia para dar cuenta sobre los motivos que mueven al movimiento de mujeres a demandar la integración del feminicidio como delito autónomo al estatuto penal, pues en este acto, lo importante no es sólo establecer la punición de una conducta sino engrosar la identidad normativa de la sociedad 0 , en términos de Durkheim, participar en la construcción de lo social. No obstante, asumir esta funcionalidad de la pena implica riesgos importantes tanto para el espíritu crítico del movimiento de mujeres como para la consolidación de un sistema penal garantista frente a los derechos de los ciudadanos. Pitch, apuntando en esta dirección, argumenta que la apuesta punitiva tiene como consecuencia "una relegitimación de la justicia penal, de su lógica, sus discursos y sus símbolos, e incluso corre el riesgo de negar 0 , al menos, de no reconocer la subjetividad femenina, reduciéndola a una simple invocación de ayuda de un grupo social reconstruido como débil y vulnerable"237.

235 Agatón, 2017, p. 157.

236 Hegel, Friedich. Filosofía del Derecho. Bueno Aires: Editorial Claridad S.A. 1968.

237 Рітсн, 2014, p. 25. 


\section{Bibliografía}

A. Adriaenseen y Aertsen. "Punitive attitudes: Towards an operationalization to measure individual punitivity in a multidimensional way". European Journal of Criminology, 12, 92-112. 2015.

A. Botтoms, "The Philosophy and Politics of Punishment and Sentencing" in The Politics of Sentencing Reform, C. Clarkson y R. Morgan (eds.). Oxford: Clarendon Press, 2000, pp. 153-216.

Agatón, Isabel. Si Adelita se fuera con otro. Del feministo y otros asuntos. Bogotá D.C.: Editorial Temis, obras jurídicas. 2017.

Alvear, Helena y Jaramillo, Isabel Cristina. Feminismo y Crítica jurídica. El análisis distributivo como alternativa crítica al legalismo liberal. Bogotá D.C.: Siglo del hombre editores/Universidad de los Andes, 2012

Amorós, Calla. "Movimientos feministas y resignificaciones lingüísticas". Quaderns de Filosofia i Ciència (30-31) pp. 7-21. p. 2002.

Ariza, Libardo y Iturralde, Manuel. "Mujer, crimen y castigo penitenciario", en Polít. crim. Vol. 12, No 24, pp. 731-753, 2017.

Ariza, Libardo y Iturralde, Manuel. Los Muros de la Infamia. Prisiones en Colombia y América Latina. Bogotá D.C.: Ediciones Uniandes. 2011.

B. Frevel. Polizei, "Politik und Medien und der Umgang mit dem bürgerschaftlichen Sicherheitsgefühl". In H. J. Lange (Ed.), Die Polizei der Gesellschaft(pp. 321336). Wiesbaden: VS Verlag für Sozialwissenschaften. 2003

Bacigalupo, Enrioue. "Filosofía e Ideología de las Teorías de la Pena". Derecho y Humanidades (16), pp. 17-30. 2010.

Baratta, Alexandro. Criminología Crítica y Crítica del Derecho Penal. Introducción a la sociología jurídico penal. Buenos Aires: Siglo Veintiuno editores. 1982.

Becaría, Cesare. Tratado de los Delitos y las Penas. Madrid: Universidad Carlos III de Madrid. 2015. P. 34.

Beckett, Katherine "Making Crime Pay: Law and Order in Contemporary American Politics". En Socia Forces (77) pp. 789-800.

Bergalli y Bodelon, "La cuestión de las mujeres y el derecho penal simbólico". Anuario de Filosofía del Derecho (ix), 1992, Madrid España, Ministerio de Justicia, 1992, pp. 43-73.

Boers. K., "Kriminalitätsfurcht - Über den Entstehungszusammenhang und die Folgen eines sozialen Problems", Hamburger Studien zur Kriminologie; 12, Pfaffenweiler: Centaurus. 1991. p.207 
Bourdieu, Pierre. "Elementos para una sociología del campo jurídico", en La Fuerza del Derecho (Bourdieu,Pierre \& Gunter Teubner) pp. 153-216. 2000.

Calvo García, M.. "The Role of Social Movements in the recognitions of gender violence as a violations of human rights: from legal reform to the lenguaje of rights". En The Age of Human Rights Journal (6) pp. 60-82. 2016.

CатоN, RоB "Crime, punishment and the moral emotions: righteous minds and their attitudes towards punishment", en Punishment \& Society (17.) Leicester UK: Montfort University. 2015.

Correa, Camila. Legítima defensa en situaciones sin confrontación: la muerte del tirano de casa. Bogotá D.C.: Ediciones Uniandes. 2017.

Costelloe. M.т. "The social correlates of punitiveness toward criminals: A comparison of the Czech Republic and Florida". Justice System Journal, 23, 191-220. 2002

Cuervo, V., Vega, L., Márouez, A. y Román V. "Feminicidio, impunidad o seguridad jurídica en la política criminal colombiana". Revista Verba luris, 12(37), pp. 109118. 2017.

D. McAdam y W. Schott, Organizations and movements. pp. 4-40, 2005.

Doomen, J.. Verkrachting Ervaringen, vooroordelen, achtergronden. Anthos, Baarn, 1976

Dowler K. "Media consumption and public attitudes toward crime and justice: The relationship between fear of crime, punitive attitudes, and perceived police effectiveness". En Journal of Criminal Justice and Popular Culture,No. 10 pp. 109-106, 2003.

Eldeman, Leachman y McAdams. "On Law, Organizations and Social Movements", en The Annual Review of Law and Social Science (85) pp. 655-685. 2010.

Fassin D. y Rechtman R.. The Empire of Trauma. An inquirí into the condition of victimhood. Pinceton University Press, 6 Oxford Street, United Kingdom. 2009.

Ferrajol, Luigi. "El Derecho Penal del Enemigo y la disolución del Derecho penal", en IUS (Verano), pp. 5-22. 2007.

FreiBerg, ArIE "Affective Versus Effective Justice: Instrumentalism and Emotionalism in Criminal Justice" en Punishment \& Society (3). Australia: University of Melbourne. 2001.

García Amado, Juan Antonio "iTienen sexo las normas? Temas y problemas de la teoría feminista del derecho" en. Anuario de Filosofía del Derecho (IX) pp. 1342., 1992

García Villegas, Mauricio. La eficacia simbólica del derecho. Sociología del campo jurídico en América Latina. Segunda edición, debate editores. Bogotá D.C. 2014. 
Garland David, "On the concept of moral panic". En Crime, Media, Culture: An international Journal (4), pp. 9-30. 2008.

GIDdens, Modernity and Self-Identity: Self and Society in the Late Modern Age. Cambridge: Cambridge Polity Press. 1991.

Gómez Jaramillo, Alejandro. Un mundo sin cárceles es posible. México: Ediciones Coyoacán. 2008.

Guzmán Rodríguez, Diana y Molano Ayala, Paola. "Ley de Cuotas en Colombia: avances y retos. Diez años de la Ley 581 de 2000". Documentos de discusión Dejusticia (13), 1-67. 2012

H.E. Russel, Diana y Radford Jill. Femicide: the politics of woman killing. New York: Twayne Publishers, 1992.

H.E. Russel, Diana. Defining Feminicide, introductory speech presented to the United Nations Symposium on Femicide. New York: ONU, 2012

Hamilton, James T. Channeling Violence: The Economic Market for Violent Televisión Programming. Princeton University Press, 1998

Hegel, Friedich. Filosofía del Derecho. Bueno Aires: Editorial Claridad S.A. 1968.

Hulsman, L. Conflcitos relativos a la terminología: "Situaciones problemática" VS. "Crimen de Investigación Cientifica. Bogotá: Universidad Externado de Colombia, 2003

Jakobs, Günther. "¿Cómo protege el Derecho penal y qué es lo que protege? Contradicción y prevención; protección de bienes jurídicos y protección de la vigencia de la norma", en los Desafíos del Derecho penal en el Siglo XXI, Libro homenaje al Profesor Dr. Günther Jakobs. Lima: Ara Editores. 2005.

Jakobs, Günther. "Sociedad, norma, persona; en una teoría de un Derecho penal funcional", traducida por Cancio Meliá y Bernardo Feijoó, en Cuadernos de conferencias y artículos No 13, Centro de Investigaciones de Derecho Penal y Filosofía del Derecho. Universidad Externado de Colombia, 1996.

Jaramillo Gómez, Alejandro, Un mundo sin cárceles es posible. México: Ediciones Coyoacán. 2008.

Jaramillo, Isabel Cristina "Reforma legal, feminismo y patriarcado en Colombia: el caso de la ley de Cuotas para mujeres en cargos de alto nivel en la Rama Ejecutiva". En Más allá del derecho. Justicia y género en America Latina, L. Cabal ed. Bogotá D.C.: Siglo del hombre editores/Center for Reproductive Rights/Universidad de los Andes, 2005, pp. 59-144 
Jaramillo, Isabel Cristina y Alfonso, Tatiana. Mujeres, cortes y medios: la reforma judicial del aborto. Bogotá D.C.: Siglo del Hombre Editores/Universidad de los Andes, 2008.

Johnson, D. "Anger about crime and support for punitive criminal justice policies". En Punisment \& Society, No.11 pp. 51-66. 2009

Judit Baer A, "Feminist Theory and the Law" en The Oxford Handbook of Law and Politics. Caldeira A.G., Kelemen D. \& Whittington E. (Eds), Oxford: Oxford Press University, 2003.

Karstedt, S. "Emotions and criminal justice". Theoretical Criminology, 6, 299-317. 2002.

KenNedY R. 1989, “Martin Luther King's constitution: a legal history of the Montgomery bus boycott". Yale Law J., pp. 999-1067, 1989.

Lagarde, Marcela. "Antropología, feminismo y Política: Violencia Feminicida y Derecho y Derechos Humanos de las Mujeres" en Retos Tenorios y Nuevas Prácticas (Bullen, Margaret (Co) \& Diez Mitegui (Co) pp. 209-238, 2008.

Lagarde, Marcela. "Antropología, Feminismo y Política: Violencia Feminicida y Derechos y Derechos Humanos de las Mujeres", en Retos Tenorios y Nuevas Prácticas (Bullen, Margaret (Co) \& Diez Mitegui (Co)). Pág. 209.238. 2008

Lagarde, Marcela. Género y feminismo. Desarrollo humano y democracia. Madrid: horas y horas, 1996.

LANGWORTHY R.H. y WhieHEAD, J.T. "Liberalism and fear as explanations for Punitiveness". En Criminology (24), pp. 575-591, 1986

LarraRul, Elena, Criminología crítica y violencia de género. Madrid: editorial trotta, 2007.

Larrauri, Elena, Mujeres y Sistema Penal. Violencia Domestica. Buenos Aires: Editorial S.R.L. 2008, p. 20.

Lehouco Mazuera, Emilio. "iQué hace el derecho en la movilización social? La movilización del movimiento de mujeres en torno a la Ley de Cuotas". En Revista de Derecho público nº 38, Universidad de los Andes, 2017.

Lehouco Mazuera, Emilıo. "Constitución de 1991, Ley de Cuotas y movimiento feminista: El papel del derecho en la generación de estructuras de movilización". Precedente, 2016, pp 13-41

Lemaitre Ripoll, Julete. El derecho como conjuro: fetichismo legal, violencia y movimientos sociales. Bogotá D.C.: Siglo del hombre editores/Univerisdad de los Andes. 2009 
Lemaitre, Julieta y K.B. Sandvik. "Shifting Frames, Vanishing Resources, and Dangerous Political Opportunities: Legal Mobilization among Displaced Women in Colombia", Law and Society Review, 49(1), pp 5-38. 2015

LOARDER, I. y Sparks, R. "The question of public criminology: seeking resources of hope for a better politics of crime" en International Annals of Criminology (Vol. 52) pp. 155-177. 2017

Mckinnon, Catherine. Unmodified: Discourses on Life and Law. Cambrige Massachusetts: Harvard University Press, 1987

Múnevar, D. I. “Delito de feminicidio. Muerte violenta de mujeres por razones de género". Estudios Socio-jurídicos [S.I. ](v. 14) pp. 135-174. 2012.

Nussbaum, Martha. Policial emotions: Why Love Matters For Justice. Cambrige, Massachusetts. Harvard University Press. 2013.

Paladines, Jorge. Feminismo punitivo, Cuando el género se redujo al castigo. Disponible en: http://www.rebelion. org/docs/174609.pdf, (Consulta: 1-06- 2014). 2013 p. 9

Piтch, T. Ressponsabilità limitate, Feltrinelli, Milán. 1989.

Piтch. T. "La violencia contra las mujeres y sus usos políticos". En Anales de la Cátedra Francisco Suárez (48) pp. 19-29, 2014

Polleta, Francesa, "The Structural Context of Novel Rights Claims: RightsInnovation in the Southern Civil Rights Movement, 1961-1966." Law and Society Review (34): pp. 367-406., 2000.

Pratt J. y Miao M. "Penal populism: the end of reason" en Nova criminis: visions cirminologicas de la justice penal (no. 13) pp. 33-105. 2018

Pratt J. "Cultura, Emoción y Castigo Penal" en Nova Criminis (5): visiones criminológicas de la justicia penal. Pp. 53-135. 2013.

Pratt, J. “Castigos ostentosos y emotivos: su declinación resurgimiento en la sociedad moderna" en Delito y sociedad: revista de ciencias sociales (22), pág. 35-56, 2006

Pratt, J. Penal Populism. London: Routledge. 2007.

ROSEnBerg y SelleR, “Número monográfico sul movimiento feminista negli anni 70". Memoria, rivista si storia delle donne. 1987.

Roxin, Claus. Offene Tatbestände und Rechtspflichtmerkmale, 2.a ed., Berlín: Walter de Gruyter. 1970.

Roxin, Claus. "El desarrollo del Derecho Penal en el siguiente siglo", en Dogmática Penal y Política Criminal, Lima: Idemsa. 1998. 
222 Mujeres, atrocidad y castigo: un estudio de caso sobre las razones del movimiento de mujeres para penalizar el feminicidio en Colombia - David Fernando Cruz Gutiérrez

Roxin, Claus. "Las formas de intervención en el delito: estado de la cuestión", en Sobre el estado de la teoría del delito (Seminario de la Universitat Pompeu Fabra), 1.a ed., Madrid: Cuadernos Civitas. 2000.

Roxin, Claus. Derecho Penal, parte general T. I (D. M. Luzón Peña, M. Díaz \& J. de Vicente Remesal, Trad.). Madrid: Civitas. 2001.

Roxin, Claus. Política criminal y sistema del derecho penal, 2.a ed., Buenos Aires: Hammurabi. 2002.

Rushe, Geor y Kircheimer, Оtтo. Punishment and Social Structure. New York: Columbia University Press. 2009

S.E Álvares. "Latin American Feminisms "Go Global": Trends of the 1990s and Challenges for the New Millennium" en S.E. Álvarez, E. Dagnino, \& A. Escober (Eds), Cultures of Politics. Politics of Culture. Re-visioning Latin American Social Movements p.p. 293.324. 1998

Sara Sun Beale, "The News Media's Influence on Criminal Justice Policy: How Market-Driven News Promotes Punitivesness" en 48 Wm. \& Mary L. Rev. 397, 2006.

Scheneiberg. "Organizational heterogeneity and the production of new forms: Politics, social movements and mutual companies in American fire insurance, 19001930". Research in the Sociology of Organizations, 19, 39-89. 2002

ScherRer. S. "Limits to Criminal Law?" en Abolitionisn, Towards a non-repressive approach to crime. Van Swaaningen R./Bianchi H. (eds.). Amsterdam: Free Universitu Press, 1989

Sergio Tonkonoff. "Acerca del crimen, el criminal y las reacciones suscita". Delito y sociedad: Revista de ciencias sociales (23) pp. 89-104. 2007

Sidney TARRow. El poder en movimiento. Los movimientos sociales, la acción colectiva y la política, Madrid, Alianza Universidad. 2017.

Sisma Mujer, Análisis de caso sobre acoso sexual y feminicidio. Bogotá D.C.: Sisma mujer. Recuperado de: http://www.sismamujer.org/wpcontent/ uploads/2016/12/01.2013.An\%C3\%A1lisis-de-Casos-sobre-AcosoSexual-y-Feminicidio-2013.pdf// 2013.

Sozzo, Máxımo "populismo penal: historia, balance, dilemas y perspectivas de un concepto" en Nova Criminis /l (14): visiones criminológicas de la Justicia Penal, pp. 79-129, 2017.

Stoeker. R. "Evaluating and Rethinking the Case Study". En The Sociological Review (39). 1991 
T.R. Tyler y R.J. Boeckmann. "Three strikes and you are out, but why? The psychology of public support for punishing rule brekers" en Law \& Soecity Review (31) 237265, 1997.

Toledo Vásquez, Patslí. Feminicidio, Consultoría para la Oficina en México del Alto Comisionado de las Naciones Unidas para los Derechos Humanos (Oacnudh), México D.F.: Organización de las Naciones Unidas. 2009.

Towsend, CHIRS. "Interaction Between the Media and the Criminal Justice System", En, The Western Australian Jurist (193) pp. 193-232, 2011.

U.J. BeIJeRSE Y R. Kools, "iApariencias engañosas? El movimiento de mujeres holandés, la violencia contra las mujeres y el sistema penal". En Mujeres, derecho penal y criminología Larrauri (eds) Madrid.. Pp. 141-166. 1990

Uprimny, Esther y Parra. Penas alucinantes. La desproporción de la penalización de las drogas en Colombia. Bogotá: Dejusticia. 2013.

VAn SoEst, M. "Eerste Nederlandsehulpcentrumvoorverkrachtevrou- wen opgericht", en wen opgericht, De Nieuwe Linie, 19. 1975

VAn SoEst, M. (1975), Eerste Nederlandsehulpcentrumvoorverkrachtevrou- wen opgericht, De Nieuwe Linie, 19 november.

Van Swannigen, R. "La política de seguridad ciudadana en Holanda. Traficando con el miedo" en Revisa española de investigación Criminológica (No. 3) pp. 1-21, 2005.

Van Swaningen R. "Femenismus und Abolitionismus als Kritik der Kriminologie", en Kriminologisches Journal Heft (3); versión en español (trad. E. Larrauri), "Feminismo, criminología y derecho penal- Una relación controvertida", en Papers d'Estudi i formació, (5) pp. 85-107., 1990.

Vásouez Gutiérrez, Juan Pablo. "La concepción de hecho social en Durkheim. De la realidad material al mundo de las representaciones colectivas". Política y Sociedad Vol. 49 (Núm 2.), pp. 331-351. 2012.

Venkatraman N. y Grant. J.H. "Construc measurement in Organizational Strategy Research: a Critique and Proposal. En Management Review 11(1): pp. 71-87" 1986

Wacouant, Loïc. Castigar a los pobres: el gobierno neoliberal de la inseguridad social. Barcelona: Gedisa. 2010

Warren, Mary Ane. "Gendercide: the implications of Sex Selection". En Totowa NJ, Rowman \& Allanheld Feminist Politics and Human Nature (viii) pp. 209. 1985 
224 Mujeres, atrocidad y castigo: un estudio de caso sobre las razones del movimiento de mujeres para penalizar el feminicidio en Colombia - David Fernando Cruz Gutiérrez

Windzio, M., Simonson, J., Pfeiffer, C., Kleimann, M. Kriminalitätswahrnehmung und Punitivität in der Bevölkerung - Welche Rolle spielen die Massenmedien? Forschungsbericht. Hannover: KFN. 2007

Zaffaroni, Eugenio Raúl, Alagia, Alejandro \& Slokar, Alejandro. Derecho Penal, Parte General. Editorial Ediar, segunda edición. Buenos Aires: ediar. 2002.

Zaffaroni, Eugenio Raúl, "El discurso feminista y el poder punitivo". In H. Birgin (Ed.), Las trampas del poder punitivo, del Género del Derecho Penal (pp. 19-37). Buenos Aires: CEADEL. 2000. 